\title{
Complex Network Analysis of CA3 Transcriptome Reveals Pathogenic and Compensatory Pathways in Refractory Temporal Lobe Epilepsy
}

\author{
Silvia Yumi Bando ${ }^{1}$, Filipi Nascimento Silva ${ }^{2}$, Luciano da Fontoura Costa ${ }^{2}$, Alexandre V. Silva ${ }^{3}$, \\ Luciana R. Pimentel-Silva ${ }^{3}$, Luiz H.M. Castro ${ }^{4}$, Hung-Tzu Wen ${ }^{5}$, Edson Amaro, Jr. ${ }^{6}$, Carlos Alberto Moreira- \\ Filho $^{1 *}$
}

1 Department of Pediatrics, Faculdade de Medicina da Universidade de São Paulo (FMUSP), São Paulo, São Paulo, Brazil, 2 Instituto de Física de São Carlos, Universidade de São Paulo, São Carlos, São Paulo, Brazil, 3 Department of Biosciences, Universidade Federal de São Paulo, Santos, São Paulo, Brazil, 4 Clinical Neurology Division, Hospital das Clínicas da FMUSP, São Paulo, São Paulo, Brazil, 5 Epilepsy Surgery Group, Hospital das Clínicas da FMUSP, São Paulo, São Paulo, Brazil, 6 Department of Radiology, Faculdade de Medicina da Universidade de São Paulo (FMUSP), São Paulo, São Paulo, Brazil

\begin{abstract}
We previously described - studying transcriptional signatures of hippocampal CA3 explants - that febrile (FS) and afebrile (NFS) forms of refractory mesial temporal lobe epilepsy constitute two distinct genomic phenotypes. That network analysis was based on a limited number (hundreds) of differentially expressed genes (DE networks) among a large set of valid transcripts (close to two tens of thousands). Here we developed a methodology for complex network visualization (3D) and analysis that allows the categorization of network nodes according to distinct hierarchical levels of gene-gene connections (node degree) and of interconnection between node neighbors (concentric node degree). Hubs are highly connected nodes, VIPs have low node degree but connect only with hubs, and high-hubs have VIP status and high overall number of connections. Studying the whole set of CA3 valid transcripts we: i) obtained complete transcriptional networks (CO) for FS and NFS phenotypic groups; ii) examined how CO and DE networks are related; iii) characterized genomic and molecular mechanisms underlying FS and NFS phenotypes, identifying potential novel targets for therapeutic interventions. We found that: i) DE hubs and VIPs are evenly distributed inside the CO networks; ii) most DE hubs and VIPs are related to synaptic transmission and neuronal excitability whereas most CO hubs, VIPs and high hubs are related to neuronal differentiation, homeostasis and neuroprotection, indicating compensatory mechanisms. Complex network visualization and analysis is a useful tool for systems biology approaches to multifactorial diseases. Network centrality observed for hubs, VIPs and high hubs of CO networks, is consistent with the network disease model, where a group of nodes whose perturbation leads to a disease phenotype occupies a central position in the network. Conceivably, the chance for exerting therapeutic effects through the modulation of particular genes will be higher if these genes are highly interconnected in transcriptional networks.
\end{abstract}

Citation: Bando SY, Silva FN, Costa LdF, Silva AV, Pimentel-Silva LR, et al. (2013) Complex Network Analysis of CA3 Transcriptome Reveals Pathogenic and Compensatory Pathways in Refractory Temporal Lobe Epilepsy. PLoS ONE 8(11): e79913. doi:10.1371/journal.pone.0079913

Editor: Ken Mills, Queen's University Belfast, United Kingdom

Received June 14, 2013; Accepted September 25, 2013; Published November 21, 2013

Copyright: (C) 2013 Bando et al. This is an open-access article distributed under the terms of the Creative Commons Attribution License, which permits unrestricted use, distribution, and reproduction in any medium, provided the original author and source are credited.

Funding: This work was funded by Fundação de Amparo à Pesquisa do Estado de São Paulo (FAPESP) research grants 2009/53443-1 and 2005/56446-0 and Conselho Nacional de Desenvolvimento Científico e Tecnológico (CNPq) grant 305635/2009-3 to CAM-F. L da FC was funded by FAPESP grants 2005/00587- 5 and 2011/50761-2 and CNPq grants 301303/06-1 and 573583/2008-0). CAM-F and L da FC are funded by FAPESP-MCT/CNPq/PRONEX grant 2011/50761-2. The funders had no role in study design, data collection and analysis, decision to publish, or preparation of the manuscript.

Competing Interests: The authors have declared that no competing interests exist.

*E-mail: carlos.moreira@hc.fm.usp.br

\section{Introduction}

Epilepsy prevalence ranges from $0.5-1.0 \%$ in developed countries to $1.4-5.7 \%$ in developing countries [1,2]. Around $30 \%$ of epileptic patients are refractory to the available antiepileptic drugs [3] and account for $80 \%$ of epilepsy cost [4]. Mesial temporal lobe epilepsy (MTLE) is the most common cause of drug-resistant epilepsy [4,5]. Prolonged febrile seizures in early childhood constitute an initial precipitating injury usually associated with MTLE [6-9]. About $40 \%$ of the patients with MTLE and a history of febrile seizures develop refractory epilepsy [10]. Surgical treatment for pharmacoresistant epilepsy has attained good results but only a minority of patients with medically refractory epilepsy are ever referred to epilepsy surgery - less than
$1 \%$ in USA [11] - and often too late to prevent serious disabilities $[11,4]$. This situation reinforces the demand for identifying genomic mechanisms underlying refractory epilepsy that can be targeted for novel preventive and drug-based therapeutic interventions [12-15].

The search for new drug-targets in epilepsy has been impacted by recent advances in functional genomics and systems biology [12-15]. Hippocampal explants obtained at epilepsy surgery constitute a valuable material for functional genomic studies because it is probable that epileptogenic genes and pathways remain active in chronic disease, since focal regions of the brain continue life-long chronically hyperexcitable [12]. Moreover, transcriptional analyses in humans and in animal models of 
chronic epilepsy portrait the disease as a disturbed network of gene-gene interactions $[12,13,15,16]$. Therefore, the study of transcriptional networks in epileptic brain tissues could be very helpful for multi-target drug discovery [12-16].

We previously described - studying transcriptional signatures of hippocampal CA3 explants obtained at epilepsy surgery - that febrile (FS) and afebrile (NFS) forms of refractory mesial temporal lobe epilepsy (RMTLE) have different pathomechanisms and constitute two distinct genomic phenotypes as shown by CA3 transcriptional co-expression networks [16]. Ex vivo high resolution magnetic resonance imaging (MRI) texture analysis of dentate gyrus (DG) also differentiates FS and NFS cases [17] and histological examination revealed that FS cases display higher neuronal cell loss in the DG granule cell layer $[16,17]$. Comparative analysis of CA3 transcriptional interaction networks revealed molecular mechanisms underlying RMTLE phenotypes and indicated potential therapeutic targets [16]. However, this network analysis was based on a limited number (hundreds) of differentially expressed genes (DE networks) among a large set of valid transcripts (close to two tens of thousands).

In transcriptional interaction networks, highly connected genes, or hubs, hold the whole network together and are either associated to specific cellular processes or link different biological processes, organizing the interactome [18-21]. Complex disease genes, such as those involved in RMTLE, usually display higher number of connections in transcriptional networks, being called broker genes because they connect many proteins that would not be otherwise connected [22]. Therefore, in order to acquire a better understanding on the molecular mechanisms underlying RMTLE genomic phenotypes it would important to develop methods to study the complete set of valid transcripts in a particular disease target tissue or cell population. The mathematical and computational tools for this task lay in the field of complex network analysis $[21,23]$.

Here we developed a methodology for complex network visualization and analysis that allows the categorization of network nodes according to distinct hierarchical levels of gene-gene connections, or node degree, and of interconnection between node neighbors, or concentric node degree (see Methods). We were thus able to study the whole set of CA3 valid transcripts in order to: i) obtain complete transcriptional networks, here called CO networks, for FS and NFS phenotypic groups; ii) examine how $\mathrm{CO}$ and DE networks are related; iii) identify genomic and molecular mechanisms underlying FS and NFS phenotypes, contributing for the discovery of potential targets for therapeutic interventions.

\section{Materials and Methods}

\section{Patients}

The RMTLE patients included in this study were selected through the CInAPCe-FAPESP Program (www.fapesp.br; www. cinapce.org.br). This research has been approved by Hospital das Clínicas da FMUSP and Hospital Albert Einstein, São Paulo, SP, Brazil institutional review boards under numbers 251/05 and CAEE 0122.0.028.174.05. A written informed consent was obtained from all patients. Refractory epilepsy cases were defined as those who have not gained seizure control after treatment with two or more antiepileptic drugs. All patients underwent preoperative clinical, electrophysiological, neuropsychological and neuroimaging evaluations. In this study we compared global gene expression profiles of CA3 explants obtained at surgery room from six FS and twelve NFS patients undergoing corticoamigdalohippocampectomy. None of these patients had mental retardation or first-degree family members with epilepsy or febrile seizure history. Detailed descriptions of the patient's demographic and clinical data and of the procedures for brain tissue collection and preservation for neuropathological (MRI and histopathology) and genomic studies (DNA microarrays) were published elsewhere [16].

\section{Brain tissue specimens for gene expression and neuropathological studies}

Fresh ex-vivo explants from hippocampal CA3 of our patients were obtained in the operating room and immediately preserved with RNAlater (Qiagen cat. no. 76106, Valencia, CA). MRI and histological studies were performed in all removed hippocampi for neuropathology analysis and for confirming that the explants for genomic studies were obtained at the proper site [16,17].

\section{RNA extraction}

Brain tissue explants from CA3 (3-4 mm3) were homogenized with TissueRupter (Qiagen, cat. no. 9001272 Valencia, CA). Total RNA was extracted from the homogenates with RNeasy Lipid Tissue Kit (Qiagen cat. no. 74804, Valencia, CA) according to manufacturer's instructions. RNA quality was assessed on the Agilent BioAnalyzer 2100 (Agilent, Santa Clara, CA). All samples were stored at $-80^{\circ} \mathrm{C}$ until used in hybridization experiments.

\section{Microarray hybridization and gene expression analysis}

In order to determine gene expression profiles, $44 \mathrm{~K}$ DNA microarrrays (Whole Human Genome Microarray Kit, Agilent Technologies, cat no. G4112F, Santa Clara, CA) were used. The procedures for hybridization followed the protocols provided by the manufacturers instructions (One-Color Microarray-Based Gene Expression Analysis - Quick Amp Labeling). The images were captured by the reader Agilent Bundle according to the parameters recommended for bioarrays and extracted by Agilent Feature Extraction software version 9.5.3, considering spots with none or only one flag (i.e. low intensity, saturation, controls, etc.). The selected transcripts were used for analysis using the $\mathrm{R}$ software version 2.11.1 (R Development Core Team, 2010) and the Lowess test for arrays normalization. We identified 15,615 valid GO annotated genes for the CA3 samples (6 FS and 12 NFS patients). By means of the TMEV software version 4.6.1 [24] we obtained 307 differentially expressed GO annotated genes using the Significance Analysis of Microarrays (SAM) procedure, all up-regulated in the FS group (fold $\geq 3.0$ ). All microarray raw data has been deposited in GEO public database (http://www.ncbi.nlm.nih.gov/geo) a MIAME compliant data base, under accession number GSE28674. Differential gene expression data were validated through quantitative real-time polymerase chain reaction [16].

\section{Transcriptional interaction network analysis}

Transcriptional interaction networks for CA3 differentially expressed GO annotated genes (DE) and CA3 transcriptional interaction complex networks for all valid GO annotated genes $(\mathrm{CO})$ were constructed for FS and NFS groups based on Pearsons correlation. Pearson correlation identifies sets of genes which covaries (positively or negatively), thus allowing us to construct networks by considering nodes as genes, with edges inferred if a pair presents high absolute value of correlation. Specifically, we define a correlation threshold that determines if edges are present or absent in the resulting network. This is done in a way that all nodes are connected to the major component and the network is stable in the sense that slight changes in the threshold value do not 
significantly affect its topological structure. It is an usual approach for constructing transcriptional interaction networks, also applied in other widely used tools (e.g. FunNet [25]). Data analysis and visualization (see below) were accomplished through the software developed by two of the authors, FNS and L da FG (http:// cyvision.if.sc.usp.br/bant/hierarchical/), which provides both dynamic and interactive data analysis of complex networks.

Concentric characterization of complex network analysis. While statistical measurements based directly on the degree present important information about the overall structure of complex networks, they fail to describe the local features of each node. The clustering coefficient [26] further extends the repertoire of complex networks measurement by considering the number of interconnections between the first neighborhoods of a node normalized by the maximum number of possible connections between them. However, the clustering coefficient may not be sufficient to distinguish between small triangles and real high clustered nodes. The node degree can be extended to consider distinct levels of hierarchy (concentric levels) from a node and obtain a measurement from each level [26-28].

Here we analyzed the networks by using the first neighborhood concentric degree and the usual node degree. This property is defined by means of concentric levels (or Rings), $R_{h}(I)$, which represent the nodes at distance $h$ from a reference node $I$. The concentric node degree, $k_{h}(I)$, of level is defined as the number of connections between $R_{h}(I)$ and $R_{h+1}(I)$. Figure 1 illustrates the concentric levels and measurements for a network example. All calculations were done by using the software available at http:// cyvision.if.sc.usp.br/ bant/hierarchical/.

Hubs and VIPs. Traditionally, nodes with particularly high number of connections - the so-called called hubs - are known to play very important roles in most of real networks [21,23]. However, in real networks, hubs may not strongly participate in some of the real networks dynamics. This is the case for

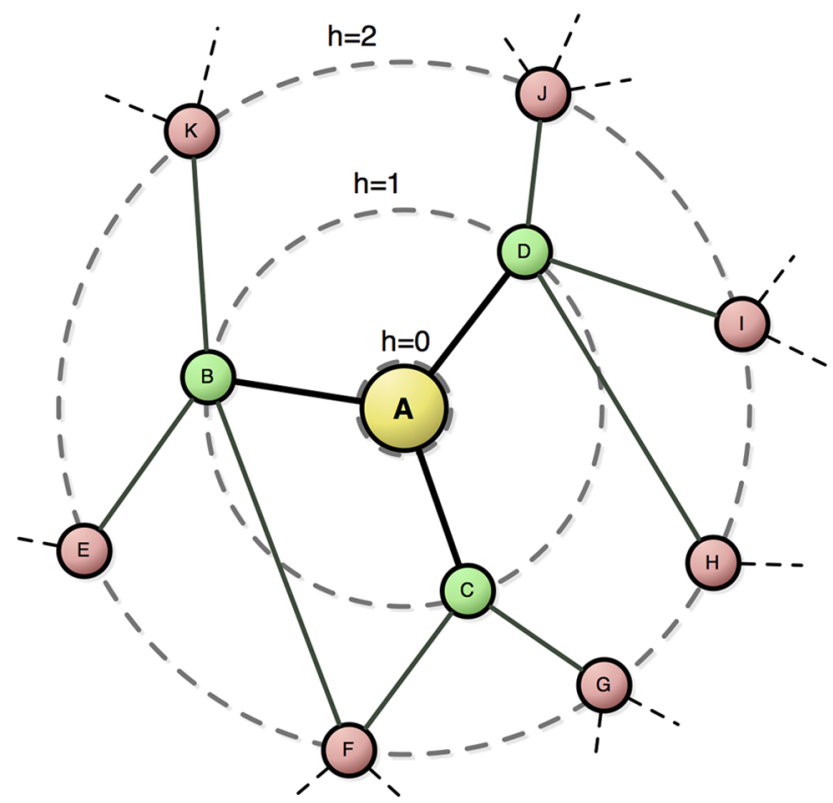

Figure 1. Concentric levels. Example of concentric levels of a network for node $A$ as reference (i.e. centered at node $A$ ). Each concentric level is represented by rings $R_{h}(A)$, namely $R_{0}(A)=\{A\}$, $R_{1}(A)=\{B, C, D\}$ and $R_{2}(A)=\{E, F, G, H, I, J, K\}$, with concentric node degrees $k_{0}(A)=3$ and $k_{1}(A)=8$.

doi:10.1371/journal.pone.0079913.g001 controllability in gene regulatory networks where hubs tend to not become driven nodes (i.e. the network controllers) [29]. There is another node category that may play an important role on such networks: the VIPS, i.e. nodes presenting low node degree but mostly connected only with hubs [30]. In some networks VIPs may represent the highest control hierarchy in a system [20] and hubs may be shadowy influenced by VIPs [31]. Some nodes may present the VIP status for being connected with the majority of the hubs in a network, and also present high overall number of connections. Here we call these nodes high-hubs, which may play even more important roles than hubs and VIPs.

One way to classify network nodes as VIPs, hubs or high-hubs is by obtaining the node degree, $k_{0}$, and the first level concentric node degree, $k_{1}$, projecting all node values in a $k_{0}$ vs $k_{1}$ graphic. VIPs should present low $k_{0}$ but high $k_{1}$, while hubs present high $k_{0}$ and low $k_{1}$, and high-hubs present high $k_{0}$ and $k_{1}$ values. Figure 2 illustrates each of these node categories.

Because most real networks present scale-free distributions, there is no clear definition for setting a degree threshold for which we can classify nodes as being hubs or not [19,21]. This same is true for objectively defining VIPs and high-hubs, since the distribution of $k_{1}$ also suffers from the problem of not presenting a scale. Here we define hubs, VIPs and high-hubs by ranking them according to $k_{0}$ and $k_{1}$, and then considering a set of those presenting the highest values of each property.

Betweenness centrality. Betweenness centrality [26,32,33] is a measurement of node importance which takes into account the entire set of shortest paths between nodes and passing through a particular node in a network. Betweenness is one of the most important topological properties of a network: nodes with the highest betweenness control most of the information flow in the network [20].

Network Visualization. Insights about the overall structure of complex networks can be obtained by projecting them into $2 \mathrm{D}$ or $3 \mathrm{D}$ spaces. This allows us not only to visualize but also to get a better understanding of which measurements and techniques may provide relevant information about these structures. In addition, inherent or calculated properties of nodes or edges can be interactively explored, providing more information than those obtained from statistical measurements such as moments and densities.

Complex networks can be visualized through projections of nodes represented as circles/balls and edges as lines/tubes connecting the nodes. Force-directed methods can be applied for visualization and are suitable for all kinds of networks, yielding visually pleasing drawings [33-35]. This method works by randomly placing the nodes over the metric space and incorporating physical forces between them, so that the structure relaxes to a minimal energy state.

We developed a software to obtain visualizations of large complex networks based on the Fruchterman-Reingold algorithm (FR) [35], which is a force-directed technique based on molecular dynamics employing both attractive and repulsive forces between nodes [36]. Each node repels each other by Coulomb forces resulting in a force $F_{(r) j}$ for each node $j \in V$, additionally, connected nodes, $(i, j) \in E$, interact by a deviation of Hooke's Law, $F_{(a) j}$, as described in Equations 1 and 2:

$$
\vec{F}_{(a) j}=\sum_{(i, j) \in E} a\left(\vec{R}_{i}-\vec{R}_{j}\right)^{2} \hat{r}_{i j}
$$




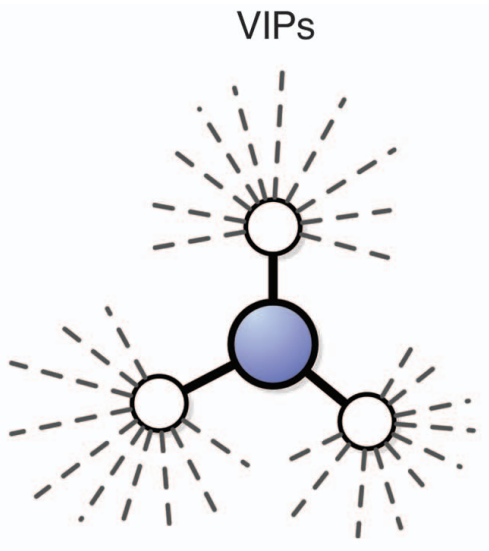

High Hubs
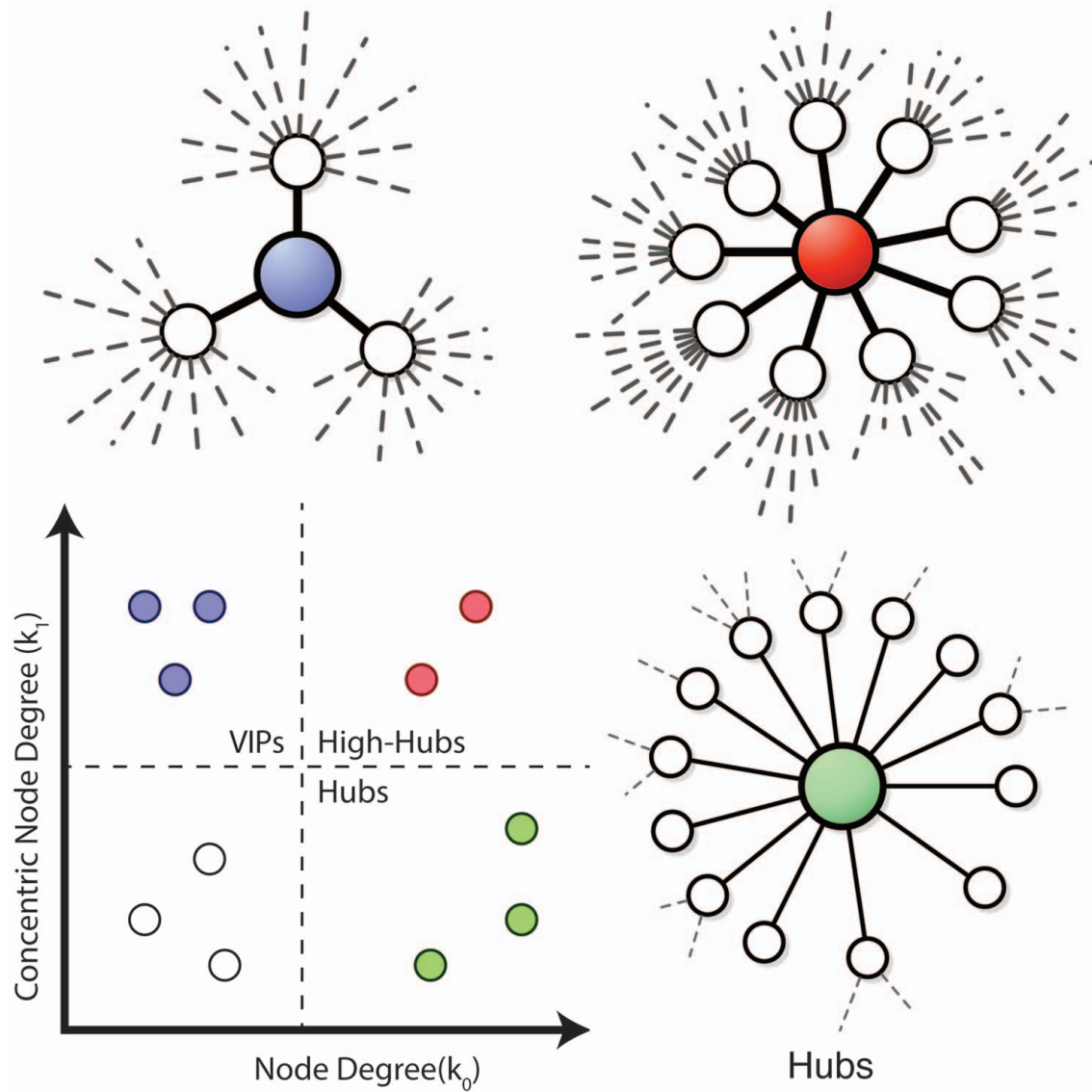

Hubs

Figure 2. Node categories. Networks illustrating the three proposed categories of nodes with VIPs presenting low node degree but high concentric node degree at first level, hubs with lower concentric node degree and higher node degree, and high-hubs presenting high values of both properties.

doi:10.1371/journal.pone.0079913.g002
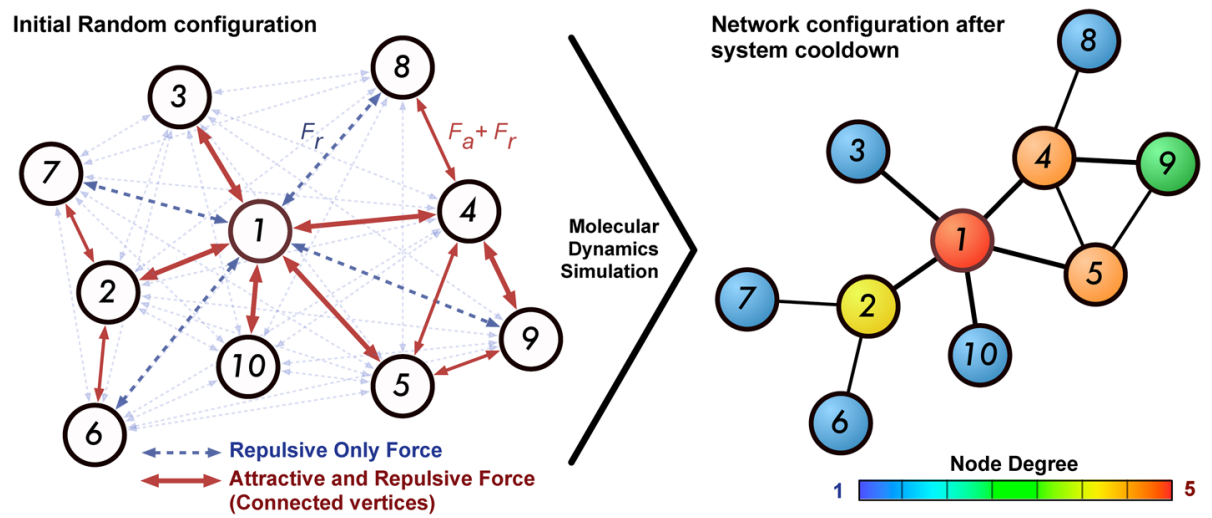

Figure 3. Network projection and visualization. On left side of the figure the network is randomly placed over the desired metric space (in this case, the 2D plane) and the forces described by equations (1) and (2) acting on each node are shown as arrows. Nodes without connection between them (displayed as fading blue arrows) interact only by repulsive forces while connected nodes (red arrows) present both attractive and repulsive interactions. Through the molecular dynamics simulation the system attains a lower energy state with connected nodes being close together if an edge is present and further away otherwise, as shown on the figure's right side. This methodology preserves the network topological structure. Final visualization is obtained by vertex color mapping according to a property or measurements, e.g. node degree. doi:10.1371/journal.pone.0079913.g003 


$$
\vec{F}_{(r) j}=\sum_{i \in V} \frac{-b}{\left(\vec{R}_{i}-\vec{R}_{j}\right)^{2}} \hat{r}_{i j}
$$

where $\vec{R}_{i}$ is the current position of node $i$ and $\hat{r}_{i j}$ is the unit vector connecting the pair of nodes, with $a$ and $b$ force constants.

By minimizing the energy of the system, one should obtain a set of positions for each vertex in a way that the preferred Euclidian distance between each connected pair is calculated by using Equation 3.

$$
d^{*}=\left(\frac{b}{a}\right)^{\frac{1}{4}}
$$

Here we chose to use molecular dynamics simulation (MDS) [37] to minimize the energy of the system. Although there are many advanced methods to discover the equilibrium states of force-directed systems, MDS is a simple approach and allow us to explore the network interactively, for instance by changing the force constants $a$ and $b$ in real time or the even the connection threshold (Fig. 3).

Our algorithm starts by assigning random positions - uniformly distributed over the desired metric space - for each node. Then the MDS equation:

$$
\frac{d^{2} \vec{R}_{i}}{d t^{2}}=\vec{F}_{(a) i}+\vec{F}_{(r) i}-\mu \frac{d \vec{R}_{i}}{d t}
$$

is solved iteratively using the traditional Runge-Kutta [38] method, where the third term acts as a viscosity force with constant $\mu$ to cool down the system and achieve an equilibrium configuration. The algorithm ends when the nodes start to move slowly because the forces are approaching null (at equilibrium distances), thus attaining a minimal energy state. The parameters $a$ and $b$ which define the magnitude of the forces also quantifies the scale of the system (see equation 3), while $\mu$ determines the time

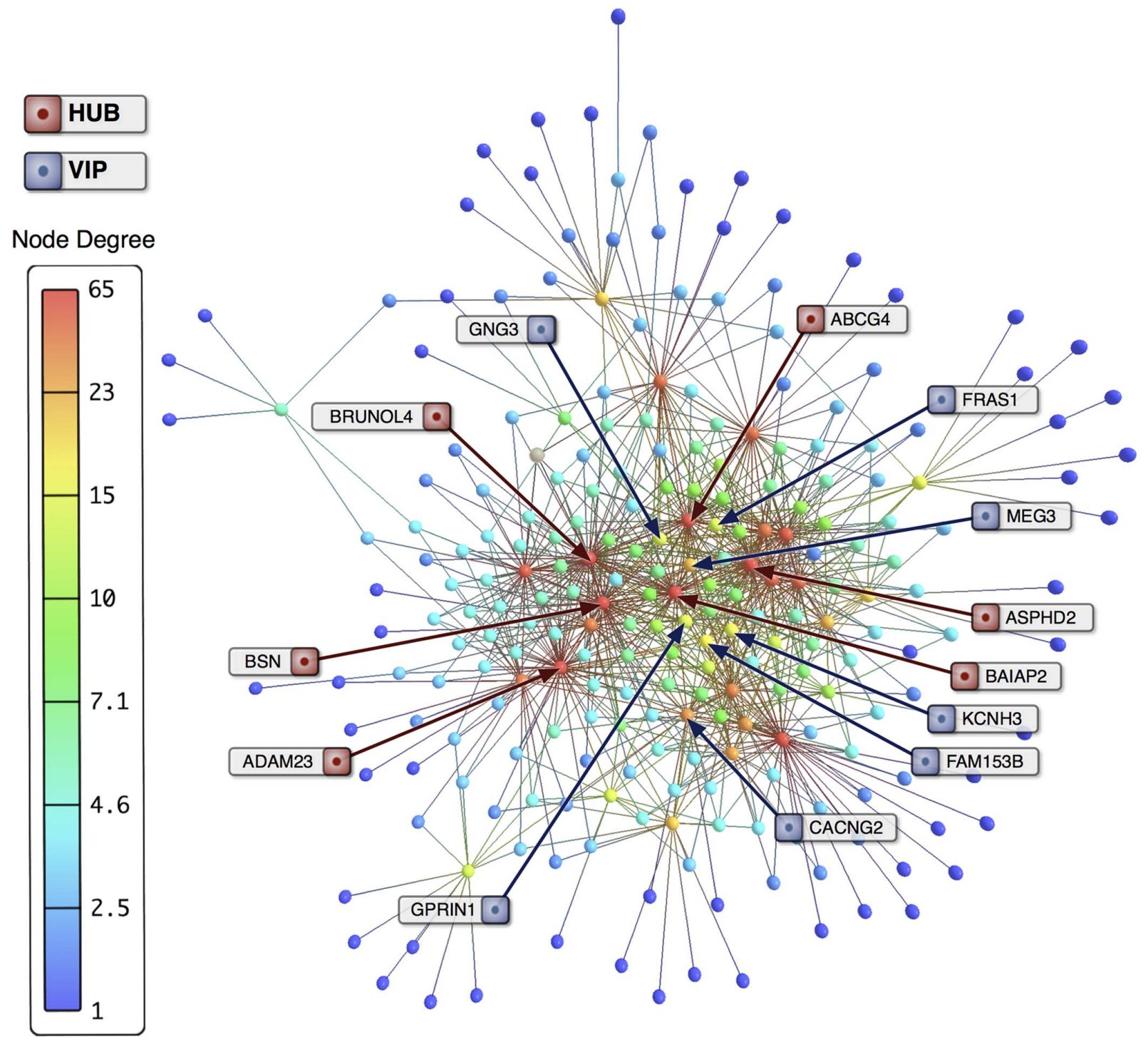

Figure 4. Transcriptional interaction network for FS group. FS transcriptional interaction network based on Pearson's correlation of 307 differentially expressed GO annotated genes (FS-DE). Hubs (red) and VIPs (blue) are identified by their gene symbols. doi:10.1371/journal.pone.0079913.g004 


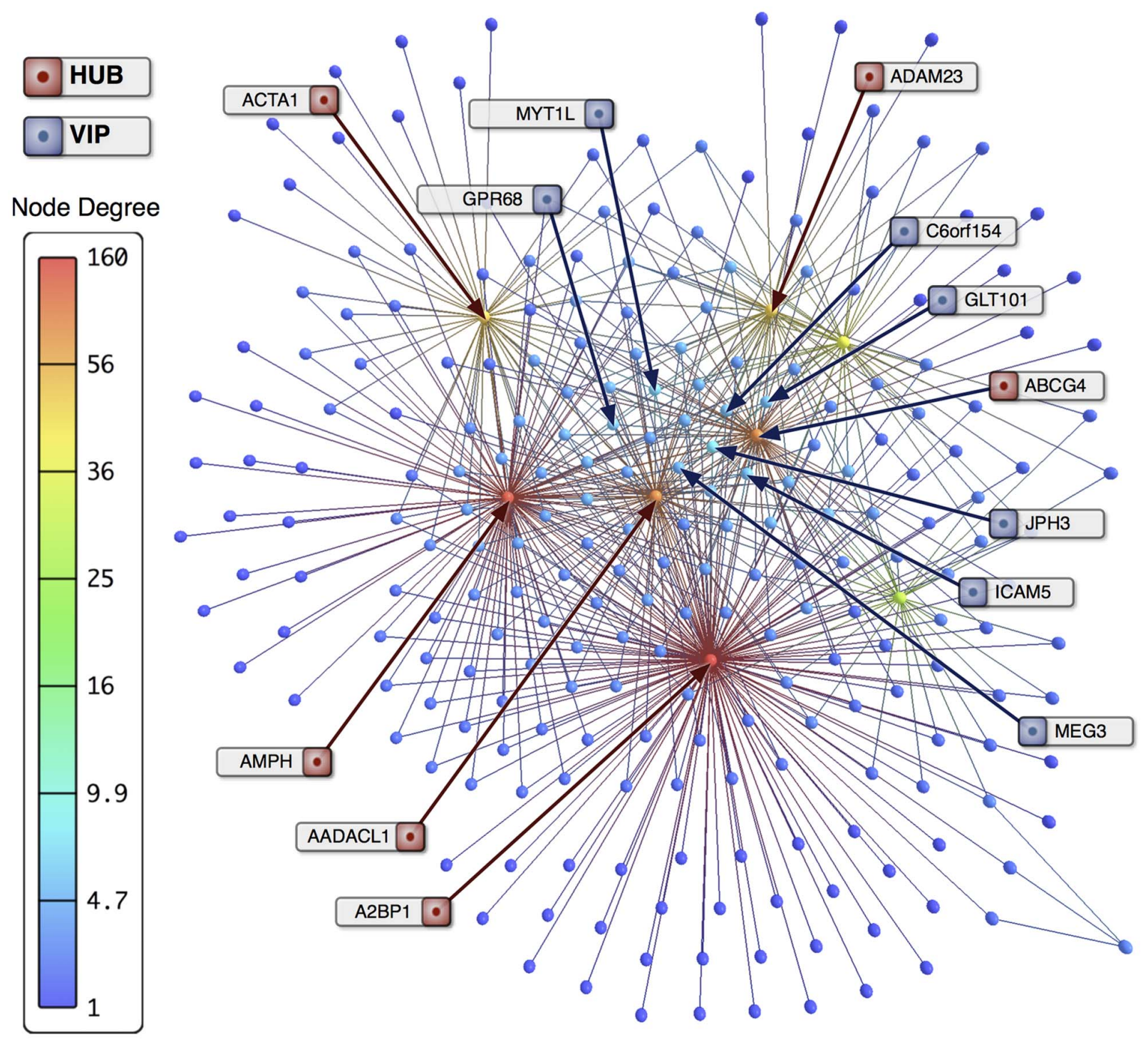

Figure 5. Transcriptional interaction network for NFS group. NFS transcriptional interaction network based on Pearson's correlation of 307 differentially expressed GO annotated genes (NFS-DE). Hubs (red) and VIPs (blue) genes are identified by their gene symbols. doi:10.1371/journal.pone.0079913.g005

that the system will take to cool down. In our implementation these parameters can be changed in real time by the user, however we found that $a=10^{-5}, b=0.1$ and $\mu=0.01$ are suitable values for most of real networks. Further optimizations [39] were made rendering this methodology computationally viable for large graph analysis.

\section{Interactome analysis}

Interactome analyses were performed for selected hubs, VIPs and high hubs in the DE and CO transcriptional networks obtained for FS and NFS groups. These analyses were carried out by using an in house free web tool developed by LA Lima \& RD Puga - Centro Internacional de Ensino e Pesquisa - Hospital A.C. Camargo and the proteins annotated in MINT, HPRD and IntAct databases (http://bioinfo.lbhc.hcancer.org.br/cgi-bin/interactom egraph/index.cgi). Data analysis and visualization were accomplished through Cytoscape v 2.8.3.

\section{Histopathology}

We used the same previously described histological processing $[16,17,40]$ in order to study a larger series of patients: in addition to the 18 cases (6 FS and 12 NFS) previously included in the genomic studies we incorporated other 12 FS and 18 NFS cases, all selected as described above. Briefly, the forty-eight formalinfixed sclerotic hippocampi were submitted to cryostat sectioning and one out five coronal slices (sixty-micron thick) of the entire hippocampus was stained with cresyl violet (Nissl). The pattern of hippocampal sclerosis was described according to Blümcke et al [41]. Semi-quantitative assessment for granule cell loss (GCL), granule cell dispersion (GCD) and granule cell bilamination (GCB) was made using four hippocampal body slices. Granule cell layer width was measured using ImageJ software (NIH, Bethesda, Maryland, USA). Immunohistochemistry for stargazin followed standard immunoperoxidase protocols for thick floating sections [40]. 
A

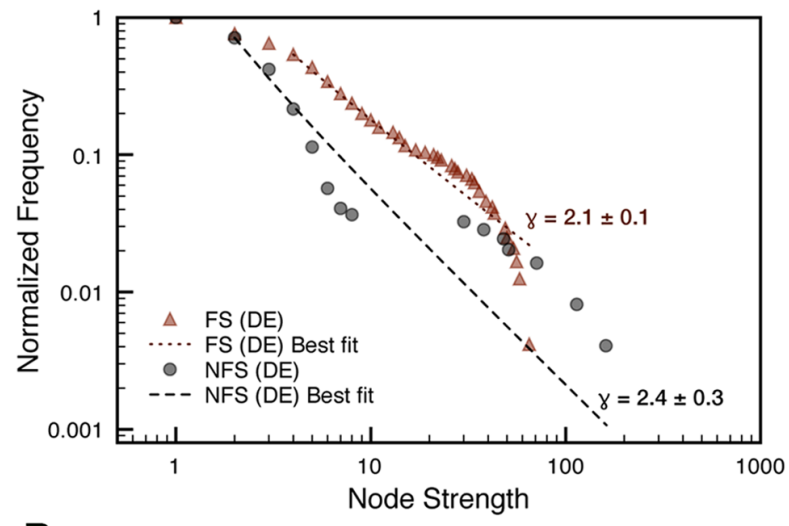

B

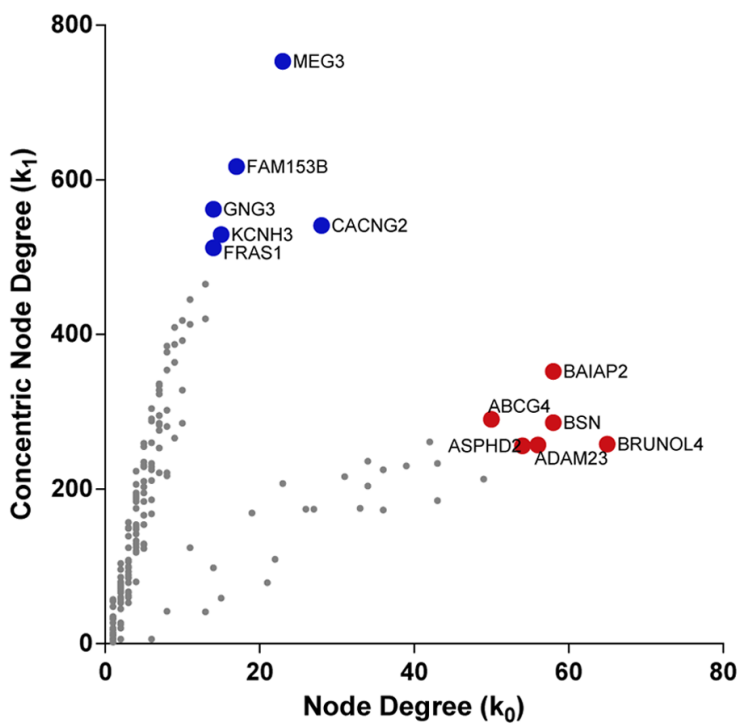

C

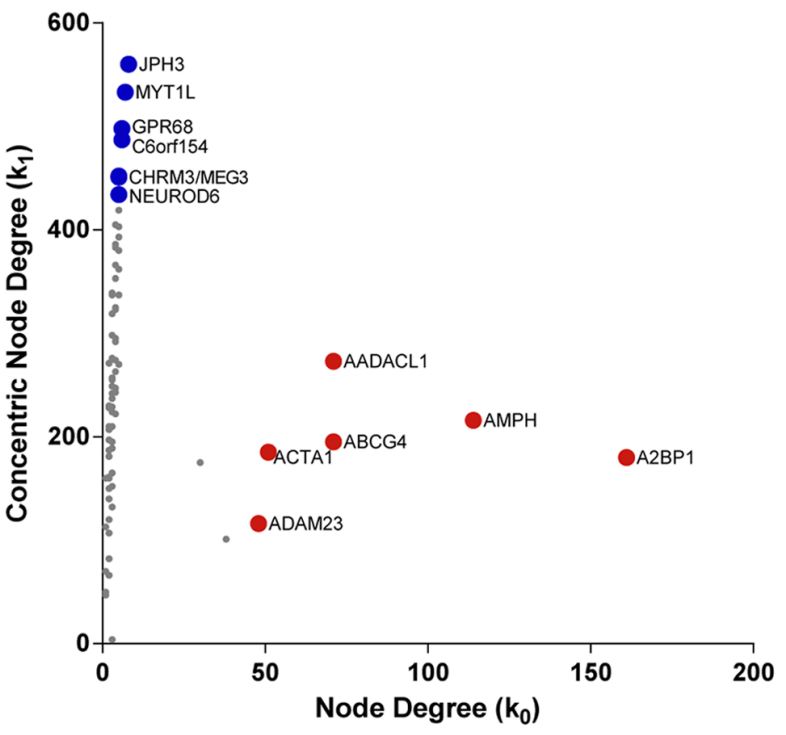

Figure 6. Node distribution and categorization for differentially expressed FS and NFS networks. Normalized degree distribution log-log plot (A) for FS and NFS differentially expressed networks, alongside their respective best fitted power law (lines), corresponding to the function $f(k) \propto k^{-\gamma}$. Scatter plot $(\mathbf{B}, \mathbf{C})$ of node degree $\left(k_{0}\right)$ vs concentric node degree $\left(k_{1}\right)$ measures of GO annotated genes obtained in the networks for differentially expressed genes (DE). Hubs (red) and VIPs (blue) genes are identified by their gene symbols. 240 nodes for the FS network (B) and 246 nodes for the NFS network (C). doi:10.1371/journal.pone.0079913.g006

\section{Results}

Transcriptional interaction networks for the 307 differentially expressed GO annotated genes (DE networks) were constructed as described in the previous section. Figs. 4 and 5 display the DE networks for FS and NFS groups respectively. Nodes are depicted in gradient color from red to blue according to decreasing node degree values. Complete transcriptional interaction networks $(\mathrm{CO})$ for 15,615 valid GO annotated genes were constructed based on Pearsons correlation. A link strength cut-off of 0.999 was adopted for FS and NFS networks, yielding a total of 15,585 GO annotated genes for the FS network and 11,233 GO annotated genes for the NFS network. In order to visualize hubs, VIPs and high-hubs in these two $\mathrm{CO}$ networks, both were displayed in 3D: videos $\mathrm{S} 1$ and S2 show the CO networks for FS and NFS groups respectively. In these videos the nodes are depicted in gradient color (red to blue) according to decreasing node degree values.

The frequency distribution of the nodes and their links (Figs. 6A and 7A) and the Kolmogorov-Smirnov test [42] confirms that the networks are indeed scale-free. Concentric categorization $\left(k_{0}\right.$ and $k_{1}$ ) was used for selection of hubs, VIPs and high-hubs, thus permitting the selection of the most connected nodes - hubs, highhubs - and of the nodes with highest $k_{1}$ values, i.e. the VIPs. The scatter plots of node degree versus concentric node degree level 1 for nodes of FS (Fig. 6B) and NFS (Fig. 6C) DE networks show the hierarchical categorization of all nodes, hence identifying nodes as hubs (high node degree) or VIPs (high concentric node degree, first level). Table 1 lists the selected genes categorized as hubs or VIPs, their corresponding betweenness centrality values and their biological function. Figs. $7 \mathrm{~B}$ and $7 \mathrm{C}$ show node hierarchical categorization for FS and NFS CO networks identifying nodes as high-hubs (high node degree and high concentric node degree, first level) hubs and VIPs. Table 2 lists the selected genes categorized as high-hubs, hubs or VIPs, their corresponding betweenness centrality values and their biological function.

\section{Transcriptional network analysis of differentially expressed genes (DE networks)}

FS-DE network. The six selected hubs in the DE network for the FS group (FS-DE network) are genes related to excitatory synaptic function (BSN, BRUNOL4, BAIAP2, and ADAM23) [4350] or to neuronal homeostasis (ABCG4 and ASPHD2) [51-53]. Three out of the six VIPs in FS-DE network - CACNG2, GNG3 and KCNH3 [54-59] - are important neuronal excitability regulators. Another relevant VIP is $M E G 3$, a maternally imprinted long noncoding RNA gene involved in neuronal differentiation [60-62], which is also a VIP in the NFS-DE network. The other two VIPs are FRAS1, related to basement membranes function and structure, as well as to cell adhesion [63], and FAM153B, that codes for a hitherto uncharacterized protein. The biological functions of these genes are summarized in Table 1 .

NFS-DE network. In the NFS-DE network five out of the six main hubs (Table 1) are related to synaptic function and hippocampal excitability: ADAM23 [49,50] and ABCG4 [51], 
A

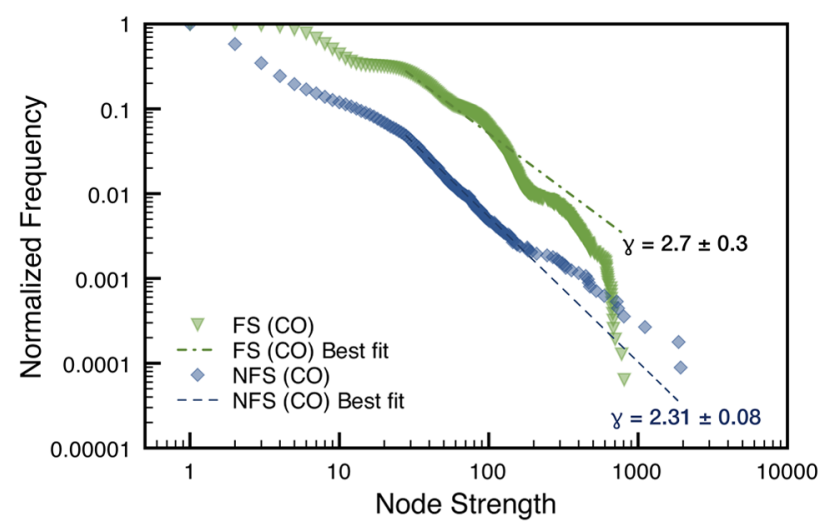

B
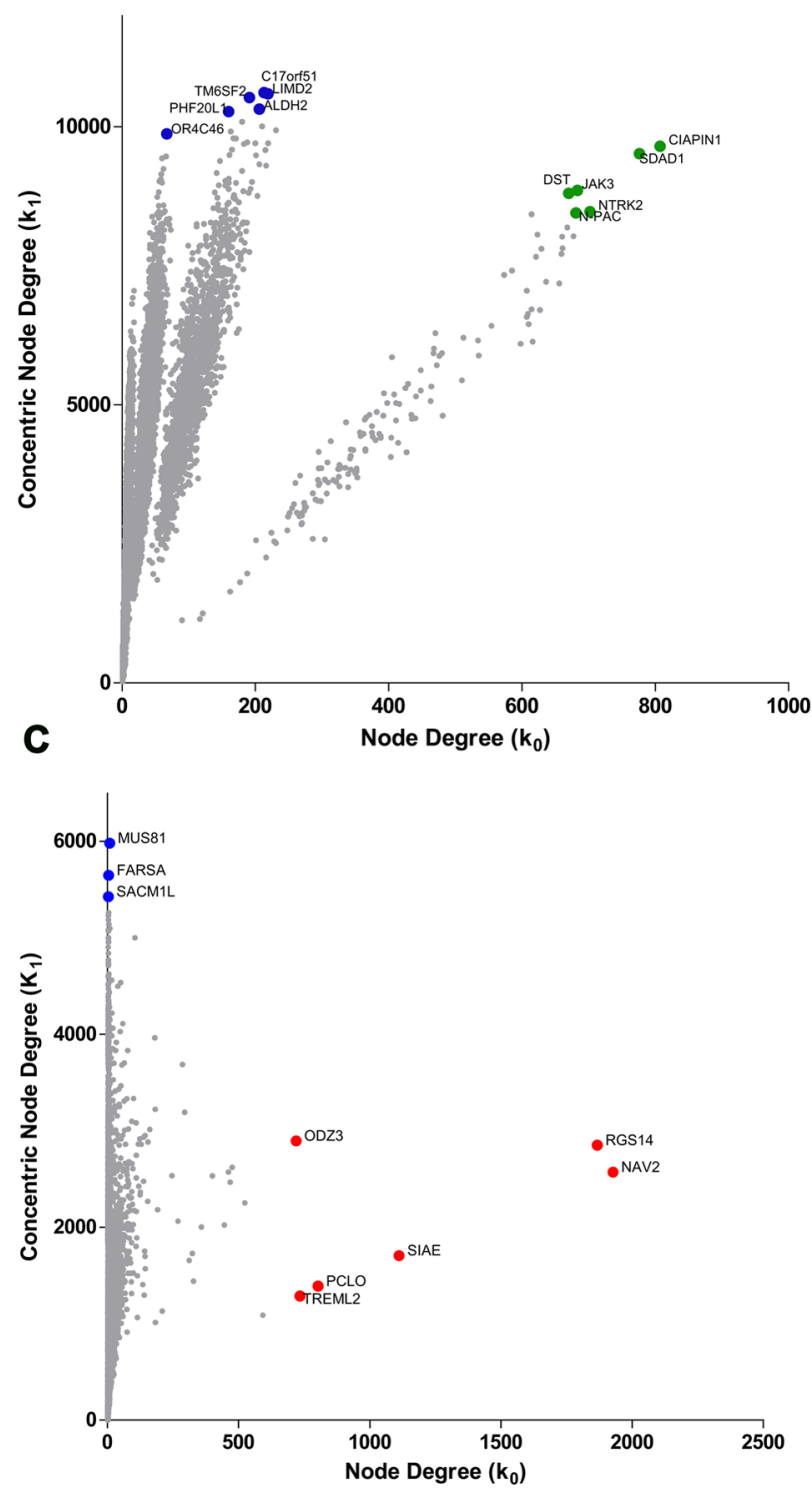

Figure 7. Node distribution and categorization for complete FS and NFS networks. Normalized degree distribution log-log plot (A) for FS and NFS complete networks, alongside their respective best fitted power law (lines), corresponding to the function $f(k) \propto k^{-\gamma}$. Scatter plot $(\mathbf{B}, \mathbf{C})$ of node degree $\left(k_{0}\right)$ vs concentric node degree $\left(k_{1}\right)$ measures of $\mathrm{GO}$ annotated genes obtained in the complete transcriptional interaction networks (CO). High-Hubs (green), Hubs (red) and Vips (blue) genes are identified by their gene symbols.15,585 nodes for the FS network (B) and 11,233 nodes for the NFS network (C). doi:10.1371/journal.pone.0079913.g007

which are also hubs in FS-DE network, A2BP1 [64], AMPH1 [65,66], and AADACL1 [67,68]. The last hub, ACTA1, codes for an actin involved in hippocampal neuronal motility regulation [69]. Three out of the seven NFS-DE network VIPs (Table 1) fPH3 [70,71], C6orf154 [72,73] and CHRM3 [74] - are related to synaptic function and neuronal excitability. The four others VIPs - MYT1L [75,76], GPR68 [77], NEUROD6 [78,79] and MEG3 [60-62] - are mostly related to neural cell maturation and hippocampal response to stress.

As a whole, DE networks hubs and VIPs encompass genes related to molecular mechanisms acting mostly on synaptic function and neuronal excitability, but also on neuronal differentiation and motility, and regulation of cholesterol efflux from neurons. All these mechanisms are altered in epilepsy and this topic will be more extensively discussed further in the present paper.

Complete transcriptional network analysis (CO networks)

FS-CO network. The selected genes of the complex network for the FS group (FS-CO) encompass only high-hubs and VIPs (Table 2). Three high-hubs - SDAD1, NTKR2 and $\mathcal{N}-P A C$ (aliase GLYR I) - are respectively involved in brain-derived neurotrophic factor (BDNF)-induced hippocampal neurite outgrowth [80,81], BDNF modulation of seizure severity and susceptibility $[82,83]$ and epigenetic regulation of BDNF upon seizures [84,85]. The other three high-hubs are: CIAPIM1, which is linked to apoptosis inhibition [86,87]; $\mathcal{F} A K 3$ that is involved in the differentiation of neural precursor cells [88] and survival of CA3 pyramidal neurons [89]; and DST, acting on neuronal cytoskeleton organization maintenance [90]. Three out of the six VIPs in the FS-CO play relevant roles in neuronal differentiation and neuroprotection (LIMD2, ALDH2 and PHF20L1) [91-96]. The fourth VIP, OR4C46, is a G-protein activated olfactory receptor [97,98]. The remaining two VIPs in this network, TM6SF2 and C17orf51, code for hitherto uncharacterized proteins.

NFS-CO network. The NFS-CO network includes hubs and VIPs, but no high-hubs. All the NFS-CO hubs - NAV2, RGS14, SIAE, PCLO, TREML2 and ODZ3 (Table 2) - are relevant for neuronal functions, particularly in the hippocampus [99-103] as it will be further discussed. The three VIPs in the NFS-CO network are associated to compensatory mechanisms, namely: MUS81, which is involved in cell survival processes [104,105]; FARSA, a gene related to axonal development of hippocampal neurons [106,107]; and SACM1L, which is highly expressed in the hippocampus and involved in astrogliogenesis [108-110].

Taken together, the hubs, high-hubs and VIPs of the CO networks are mostly related to hippocampal neuronal functions, acting either on normal or pathological processes (such as epilepsy) that take place in different hippocampal structures. Complete network analyses bring a potential contribution to understanding neurodevelopmental alterations in epileptogenesis. This issue will be detailed more extensively in the Discussion section.

\section{Interactome analysis}

We performed an interactome analysis in order to validate the selected hubs, VIPs and high-hubs in DE and CO networks. Fig. 8 
Table 1. Genes categorized as hubs or VIPs in FS and/or NFS transcriptional interaction networks for differentially expressed genes (DE networks).

\begin{tabular}{|c|c|c|c|c|c|}
\hline \multirow[b]{2}{*}{ Gene } & \multicolumn{2}{|l|}{ FS } & \multicolumn{2}{|l|}{ NFS } & \multirow[b]{2}{*}{ Gene function and/or product [reference] } \\
\hline & Cat $^{\mathbf{a}}$ & Bt $\mathbf{C t}^{\mathbf{b}}$ & Cat & Bt Ct & \\
\hline$B S N$ & Hub & 0.078 & & 0.001 & Bassoon - Speeding of vesicle reloading at excitatory synapses. [44] \\
\hline ADAM23 & Hub & 0.108 & Hub & 0.029 & $\begin{array}{l}\text { Patterning of hippocampal neuronal morphology; interacts with the antiepileptogenic } \\
\text { protein LGI1 [50] }\end{array}$ \\
\hline BRUNOL4 & Hub & 0.091 & & 0.001 & Regulation of genes related to synaptic function [47] \\
\hline ASPHD2 & Hub & 0.054 & & & Transmembrane protein involved in regulating neuronal motility [53] \\
\hline BAIAP2 & Hub & 0.075 & & 0.002 & $\begin{array}{l}\text { Regulation of NMDA receptor-mediated excitatory synaptic transmission, LTP, and learning } \\
\text { and memory behaviors [48] }\end{array}$ \\
\hline$A B C G 4$ & Hub & 0.055 & Hub & 0.119 & Regulation of neuronal cholesterol efflux [51] \\
\hline MEG3 & VIP & 0.117 & VIP & 0.002 & $\begin{array}{l}\text { Maternally imprinted long noncoding RNA [60] expressed in the pyramidal cell layer of the } \\
\text { hippocampus with a putative role in neuronal development/differentiation [117] }\end{array}$ \\
\hline FAM153B & VIP & 0.016 & & 0.000 & Family with sequence similarity 153 , member B \\
\hline GNG3 & VIP & 0.014 & & 0.001 & $\begin{array}{l}\text { G protein gamma 3, abundantly and widely expressed in the brain, required for } G_{A B A_{B} R} \\
\text { regulation of neuronal excitability; modulator of seizure susceptibility [57] }\end{array}$ \\
\hline CACNG2 & VIP & 0.102 & & & $\begin{array}{l}\text { Codes for stargazin, a receptor regulatory protein that controls the surface and synaptic } \\
\text { expression of AMPA type glutamate receptors (AMPARs) [54]. An increase in stargazin } \\
\text { expression may be pro-epileptic [16,55] }\end{array}$ \\
\hline KCNH3 & VIP & 0.014 & & & $\begin{array}{l}\text { Regulation of excitability in hippocampal pyramidal neurons. Alterations in this gene cause } \\
\text { epilepsy [59] }\end{array}$ \\
\hline FRAS1 & VIP & 0.042 & & 0.000 & Structure and function of basement membranes; cell adhesion [63] \\
\hline$A 2 B P 1$ & & 0.078 & Hub & 0.532 & $\begin{array}{l}\text { Codes for the splicing-regulator Rbfox } 1 \text { and controls neuronal excitation in the mammalian } \\
\text { brain [64] }\end{array}$ \\
\hline AMPH1 & & 0.069 & Hub & 0.324 & Regulation of endocytic recycling/synaptic vesicle endocytosis $[65,66]$ \\
\hline AADACL1 & & 0.083 & Hub & 0.112 & $\begin{array}{l}\text { Brain serine hydrolase; regulates de novo formation of PAF [67] controlling hippocampal } \\
\text { hyperexcitability [68] }\end{array}$ \\
\hline ACTA1 & & 0.031 & Hub & 0.102 & Actin involved in the regulation of neuronal motility [69] \\
\hline JPH3 & & 0.001 & VIP & 0.006 & Junctophilin 3; involved in the control of hippocampal neuronal excitability [68] \\
\hline MYT1L & & 0.000 & VIP & 0.005 & $\begin{array}{l}\text { Transcription factor involved in neurogenesis, neural cell maturation/functionality; } \\
\text { differentiation of dopaminergic neurons [76] }\end{array}$ \\
\hline GPR68 & & 0.000 & VIP & 0.004 & Proton $(\mathrm{pH})$ sensing $\mathrm{G}$ protein-coupled receptor regulating reactive astrogliosis [77] \\
\hline C6orf154 & & 0.043 & VIP & 0.003 & $\begin{array}{l}\text { Codifies a leucine rich repeat containing protein (LRR); LRRs are involved in controlling } \\
\text { hippocampal synaptic functions }[72,73]\end{array}$ \\
\hline CHRM3 & & 0.000 & VIP & 0.002 & Cholinergic neuromodulation of hippocampal circuitry [74] \\
\hline NEUROD6 & & 0.001 & VIP & 0.003 & Neuronal differentiation and stress tolerance [79] \\
\hline
\end{tabular}

${ }^{a}$ Node category: Hub or VIP; ${ }^{\text {b } B e t w e e n n e s s ~ c e n t r a l i t y ~ m e a s u r e . ~}$

doi:10.1371/journal.pone.0079913.t001

(A-D) shows the interactome networks for DE and CO networks of FS and NFS groups. In NFS-DE interactome network, a hub ACTAl (also hub in NFS-DE transcriptional network) codifies an actin filament. Conversely, in FS-CO interactome network, a main hub JAK3 (which is a high-hub in FS-CO transcriptional network) codifies a tyrosine kinase. Because these proteins are commonly involved in many cell process pathways, we selected nodes and links for interactome analysis adopting the first and second hierarchical levels centered in the DE or CO transcriptional VIPs (links in red in Figs. 8B and 8C). A description of biological process and/or function based on Gene Ontology database of selected proteins is presented in Tables $\mathrm{S} 1-\mathrm{S} 4$.

\section{Histopathology}

GCL severity was higher $(\mathrm{p}<0.05)$ in FS group (Fig. 9A). Differences between FS and NFS groups regarding mesial temporal sclerosis types, GCD severity (Fig. 9E) and GCB occurrence (Fig. 9F) were not statistically significant. Immunohis- tochemistry confirmed tissue presence of stargazin (coded by the gene CACNG2, a VIP in the FS-DE network) and quantitative analysis revealed higher expression of this protein in FS cases when compared to NFS group. Stargazin immunoreactivity was observed in the soma of pyramidal cells of cornu ammonis and subiculum, granule cells and hylar neurons of the dentate gyrus (Fig. 9G). Neuronal processes and perisomatic staining were also observed in principal cell layers. In FS cases immunoreactivity was higher in CAl $(p=0.0004)$, CA3 $(p=0.0007)$ and granule cell layer $(p=0.0012)$, when compared to NFS group. A detailed analysis of hippocampal neuropathology and immunocytochemistry findings in this series of patients will be published elsewhere.

\section{Discussion}

In this paper we developed a methodology for: i) transcriptional interaction network analysis of differentially expressed noncategorized GO annotated genes; ii) global transcriptional interaction analysis - encompassing all valid GO annotated genes 
Table 2. Genes categorized as high-hubs, hubs or VIPs in FS and/or NFS complete transcriptional interaction networks (CO).

\begin{tabular}{|c|c|c|c|c|c|}
\hline \multirow[b]{2}{*}{ Gene } & \multicolumn{2}{|l|}{ FS } & \multicolumn{2}{|l|}{ NFS } & \multirow[b]{2}{*}{ Gene function and/or product [reference] } \\
\hline & Cat $^{\mathbf{a}}$ & Bt $\mathbf{C t}^{\mathbf{b}}$ & Cat & Bt Ct & \\
\hline CIAPIN1 & Hhub & 0.022 & & 0.000 & $\begin{array}{l}\text { Cytokine-induced inhibitor of apoptosis; protection of hippocampal dopaminergic } \\
\text { neurons [90] }\end{array}$ \\
\hline SDAD1 & Hhub & 0.02 & & 0.000 & Ribosome biogenesis [83] and hippocampal neurite outgrowth [84] \\
\hline JAK3 & Hhub & 0.017 & & 0.000 & $\begin{array}{l}\text { Non-receptor tyrosin kinase; involved in proliferation/differentiation of neural precursor } \\
\text { cells [91] and survival of CA3 pyramidal neurons [92] }\end{array}$ \\
\hline NTRK2 & Hhub & 0.014 & & 0.003 & $\begin{array}{l}\text { Brain-derived neurotrophic factor (BDNF) receptor; involved in epileptogenesis and in } \\
\text { hippocampal synaptic plasticity }[85,86]\end{array}$ \\
\hline DST & Hhub & 0,012 & & 0,005 & $\begin{array}{l}\text { Dystonin; cytoskeletal linker protein essential for maintaining neuronal cytoskeleton } \\
\text { organization [93] }\end{array}$ \\
\hline N-PAC & Hhub & 0,015 & & 0.000 & Regulation of histone demethylation [133] \\
\hline C17orf51 & VIP & 0,001 & & 0.000 & chromosome 17 open reading frame 51 \\
\hline LIMD2 & VIP & 0,001 & & 0,001 & Regulation of neural patterning and differentiation of specific axonal projections [95] \\
\hline ALDH2 & VIP & 0,001 & & 0.000 & Protection of hippocampal neurons from oxidative stress [96] \\
\hline TM6SF2 & VIP & 0,001 & & 0.000 & Transmembrane 6 superfamily member 2; Gene ID: 53345 \\
\hline PHF2OL1 & VIP & 0,001 & & 0.000 & $\begin{array}{l}\text { PHD finger; histone reader protein; mediates molecular interactions in gene transcription; } \\
\text { involved in neuronal differentiation }[58,99]\end{array}$ \\
\hline OR4C46 & VIP & 0.000 & & 0.000 & Putatively involved in regulation of synaptic efficacy $[100,101]$ \\
\hline NAV2 & & & Hub & 0.230 & Neurite outgrowth and axonal elongation [102] \\
\hline RGS14 & & 0.000 & Hub & 0.225 & Interfaces hippocampal signalling and synaptic plasticity [103] \\
\hline SIAE & & 0.000 & Hub & 0.121 & $\begin{array}{l}\text { Sialic acid acetyl esterase; sialic acid is involved in the modulation of hippocampal neural } \\
\text { and network excitability [104] }\end{array}$ \\
\hline PCLO & & 0.000 & Hub & 0,085 & Maintenance of synaptic vesicle clustering; plays a redundant role with BSN [45] \\
\hline TREML2 & & 0,004 & Hub & 0.076 & Ligand in phagocytosis of apoptotic neuronal cells by microglia [106] \\
\hline ODZ3 & & 0,003 & Hub & 0.070 & Regulator of neural connectivity [105] \\
\hline MUS81 & & 0.000 & VIP & 0.001 & DNA recombination repair endonuclease [107] maintenance of ALT cell survival [108] \\
\hline FARSA & & 0.000 & VIP & 0.001 & $\begin{array}{l}\text { tRNA phe; aminoacyl-tRNA synthetases are required for axonal development in } \\
\text { hippocampal motor neurons [109] }\end{array}$ \\
\hline SACM1L & & 0.000 & VIP & 0.002 & $\begin{array}{l}\text { Highly expressed in hippocampus; shares sequence homology with synaptojanins [111] } \\
\text { and is involved in astrogliogenesis [113]. }\end{array}$ \\
\hline
\end{tabular}

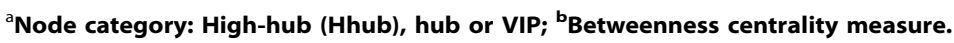

doi:10.1371/journal.pone.0079913.t002

- based on complex network 3D visualization; iii) concentric characterization measuring and node hierarchical categorization. This methodological approach allowed us to: i) construct transcriptional networks for differentially expressed genes without previous gene classification in thematic groups (a bias present in widely used tools, as FunNet [25]); ii) construct global transcriptional networks through new $3 \mathrm{D}$ visualization techniques which revealed the global structure of such networks, with emphasis on gene-gene interaction categorization and network topology.

The presented methodology was already been proved to be useful in other knowledge fields [111], however it still novel when analyzing transcriptional networks. The 3D interactive visualization technique allowed us to explore the networks topology and provided good starting points to find interesting features such as the VIP and hub classification.

Here we used this complex network analysis methodology in order to investigate the genomic and molecular mechanisms underlying FS and NFS phenotypes in RTMLE. This approach allowed the analysis of all hippocampal CA3 valid transcripts and the disclosure of a more complete gene-gene interconnectivity pattern in the target tissue. Complex network visualization and analysis, with concomitant node categorization as hubs, high-hubs or VIPs, for each phenotype is critical: in complex diseases, like acquired epilepsy, that are determined by the interplay of genes and environmental factors, the role of the disease-genes (brokers) depends substantially on their gene-gene connectivity and much less on structural gene alterations [15,21,22]. Moreover, transcriptional analyses limited to differentially expressed genes do not capture the relevance of interconnectivity based on genes that differ less in their expression and more in their degree of connectivity with other genes. This classification approach presented to be even more informative than the usual way of ranking genes, which relies on their global centrality and immediate number of neighbors, thus revealing only information about the extremes in the scales of the network (respectively, global and strictly local properties).

When a gene-gene interaction network in a disease target tissue suffers a perturbation caused by environmental factors this perturbation triggers a succession of events. In febrile RTMLE, for instance, the release of inflammatory mediators probably drives coordinate changes in the functioning of hundreds of genes in the brain [9]. This process of change is certainly not limited to epileptogenesis but remains throughout the disease duration. In this context, gene functioning reflects both pathogenic and compensatory mechanisms. Correlating changes in transcriptional complex networks with different pathophenotypes may be helpful 
A

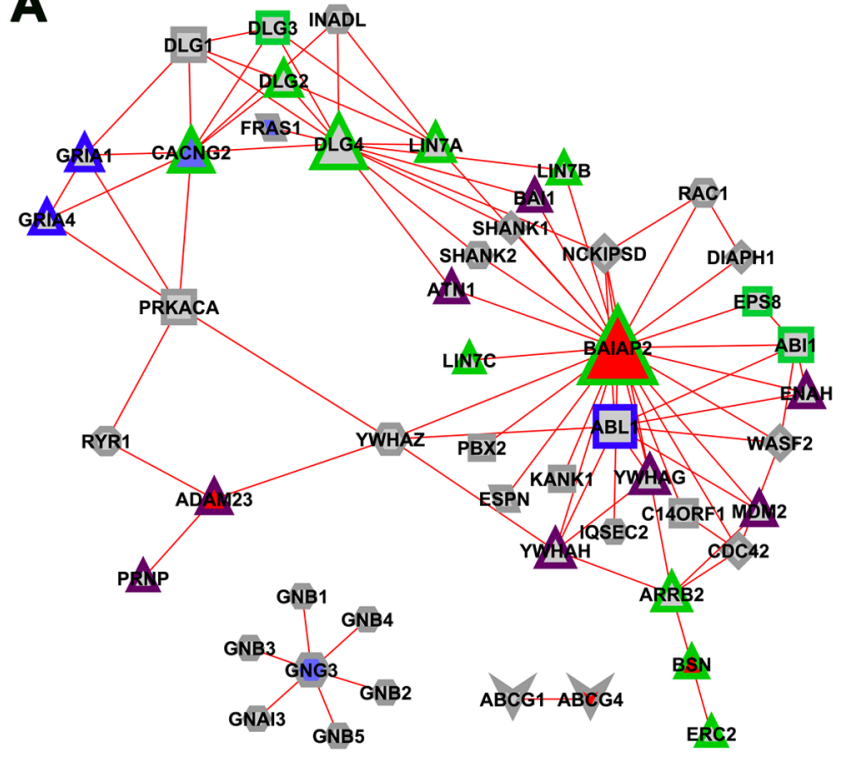

C

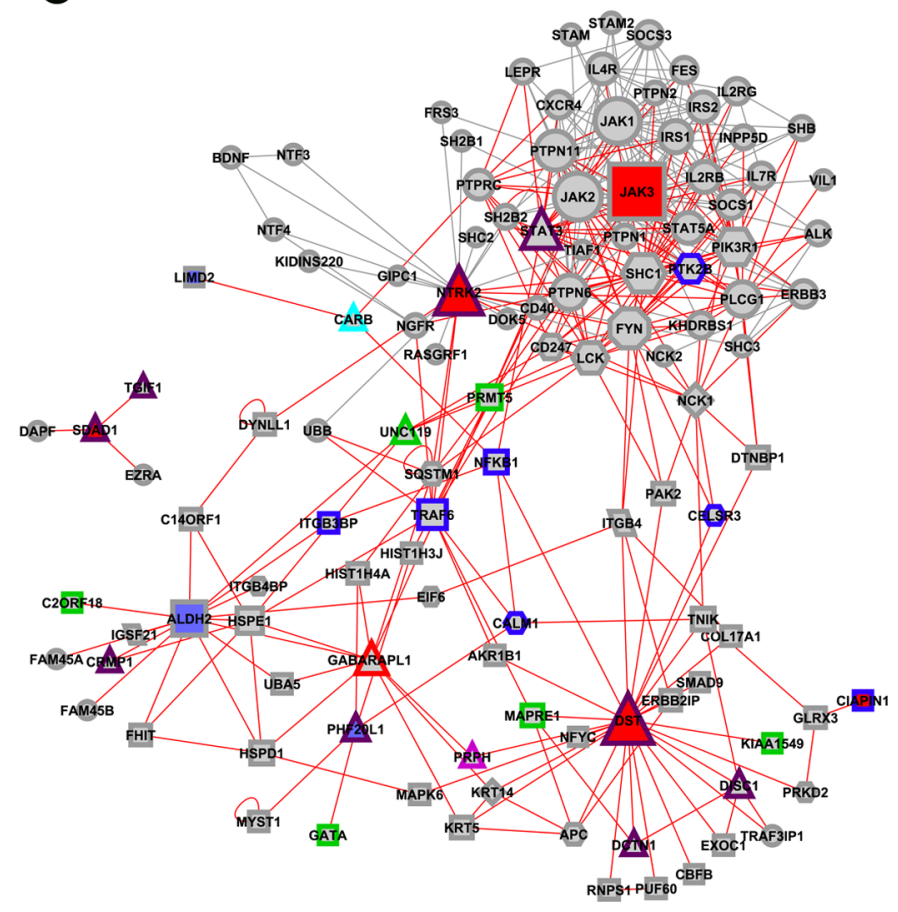

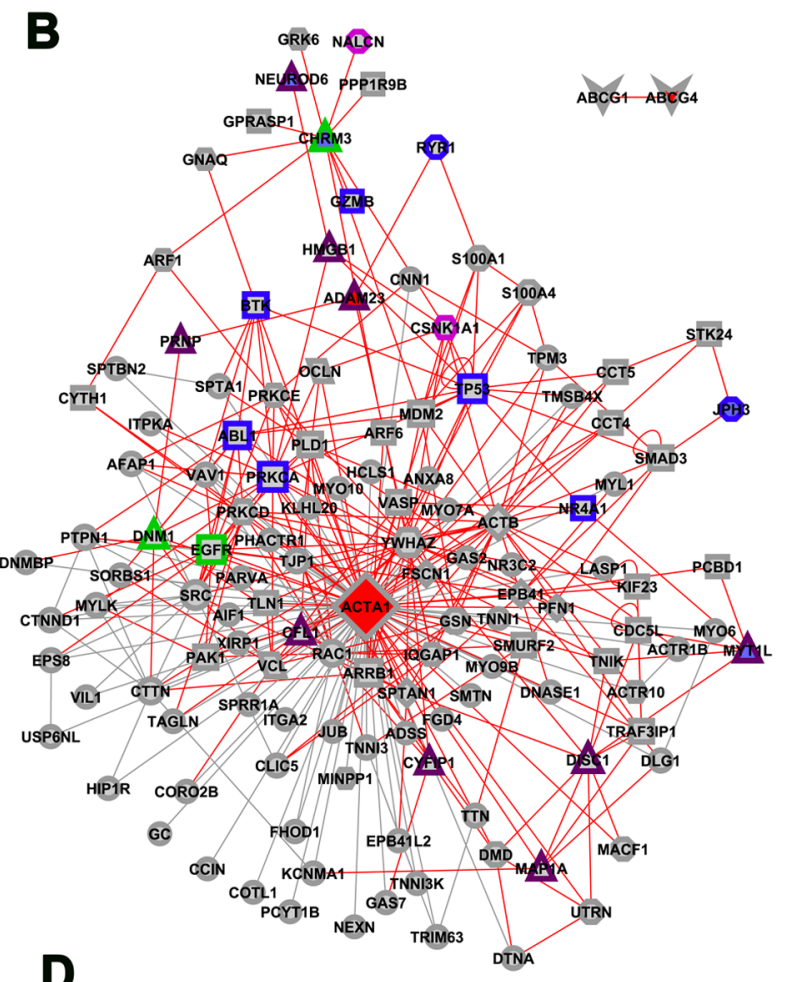

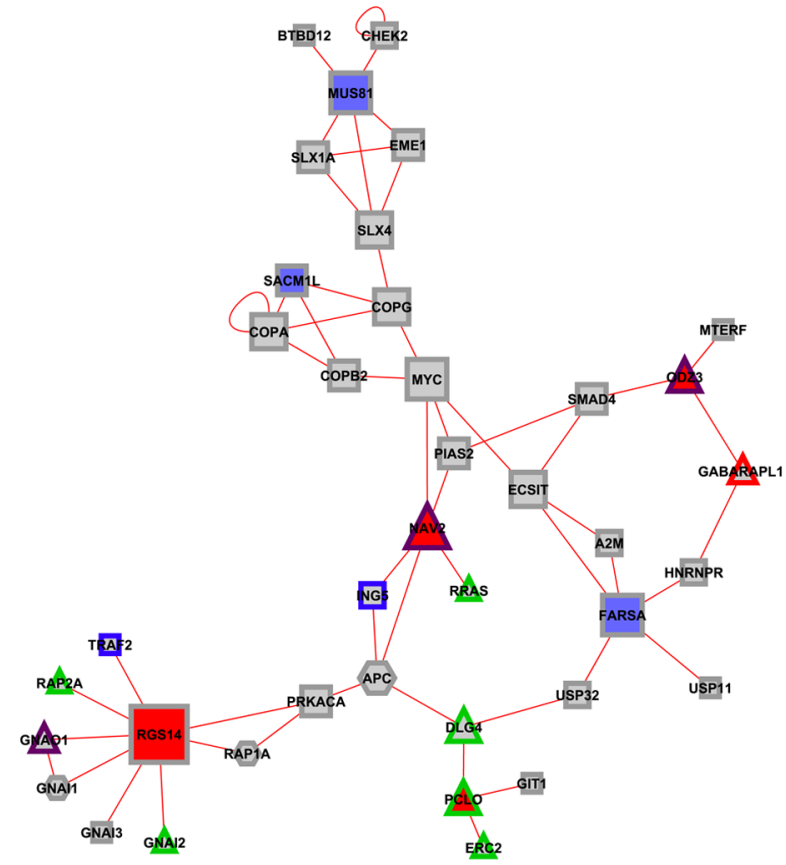

Figure 8. Interactome networks. Interactome networks for DE (A, B) and CO (C, D) hubs/high-hubs (depicted in red) and VIPs (depicted in blue) using MINT, HPRD and IntAct databases for FS (A, C) and NFS (B, D) groups. Node shapes and colors represent biological processes, as follows: diamond for actin/cytoskeleton; hexagon for signaling (blue or pink borders stands for neurotransmission or inflammation); octagon for calcium ion binding/transport/homeostasis; octagon with blue or pink border stand for cation channel or cation transport respectively; parallelogram for cell-cell interaction/adhesion; rectangle for cell processes (blue or green borders stand for apoptosis or proliferation); bordered triangles stand for synaptic transmission/SNARE complex (light blue), voltage-gated ion channel activity (pink), GABAergic synaptic transmission (red), synaptic transmission (green) and neuronal differentiation/motility (purple); vee for cholesterol homeostasis; ellipse for other processes. Nodes in red represent high-hubs or hubs in CO or DE transcriptional networks, respectively; Nodes in blue represent VIPs in CO and DE transcriptional networks; Node size is related to node degree (number of links). Links in red represent the first and second hub connections, centered in DE or CO VIPs. doi:10.1371/journal.pone.0079913.g008 
A

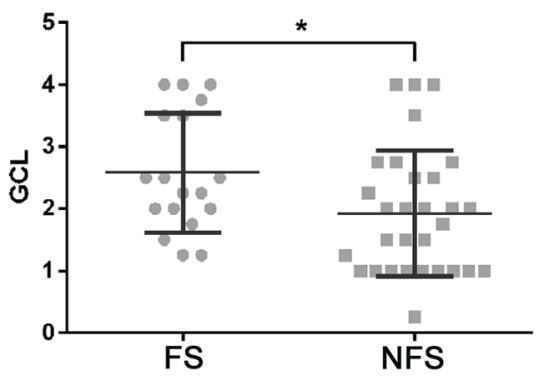

B

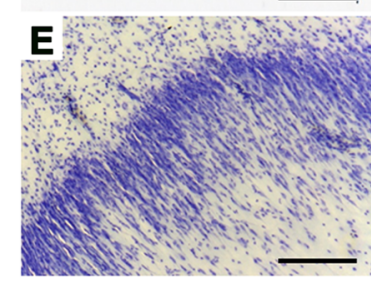

C

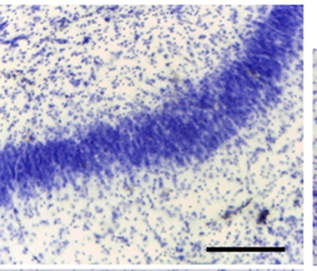

$\mathbf{F}$

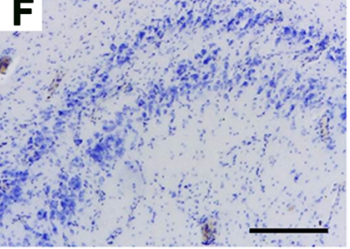

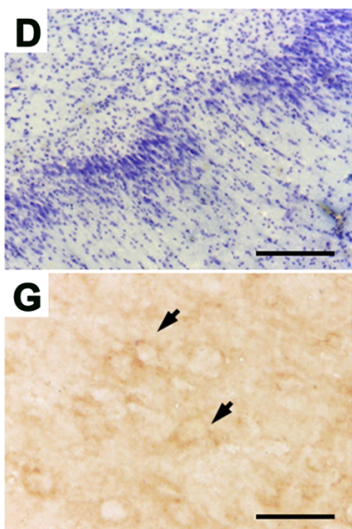

Figure 9. Histopathological results. Histopathological findings in sclerotic hippocampi from patients with epilepsy and semiquantitative analysis of granule cell loss $(\mathrm{GCL})$ in patients with (FS) or without (NFS) febrile seizures as initial precipitant insult. A: semiquantitative analysis of granule cell loss (GCL) in patients with (FS) or without (NFS) febrile seizures as initial precipitant insult $(*: p<0.05)$. B: overview of a histological slice. C: preserved granule cell layer. D: granule cell loss. E: granule cell dispersion. F: granule cell bilamination. G: stargazin-positive cells (arrows). Calibration bars: B $4 \mathrm{~mm}$; C-F 200 um; G 50 um. GCL was graded into the following categories: grade zero (no GCL), grade 1 (mild reduction of neuronal density), grade 2 (moderate reduction of neuronal density), grade 3 (severe reduction of neuronal density), and grade 4 (disruption of neuronal cell layer). doi:10.1371/journal.pone.0079913.g009

for finding novel potential therapeutic targets and design intervention strategies.

Joint visualization and analysis of $\mathrm{CO}$ and $\mathrm{DE}$ networks revealed that DE hubs and VIPs are evenly distributed inside the $\mathrm{CO}$ networks (i.e., not as clusters), as shown in videos $\mathrm{S} 1$ and $\mathrm{S} 2$. Nonetheless, in spite of this shared network topology, the sets of hubs, VIPs and high-hubs of DE and CO networks have somewhat different profiles regarding their biological functions and/or presence in specific molecular pathways, as discussed below.

\section{DE networks}

Considering only the genes with known biological functions in DE networks (i.e. 20 out of 22, see Table 1), four out of the six hubs in FS-DE network are related to synaptic transmission and neuronal excitability, as well as three out of the five VIPs. In NFSDE network the situation is quite similar: four out of six hubs and three out of five VIPs have this functional profile, totalizing 13 out 20 genes in both networks (ADAM23 and ABCG4 are common hubs and MEG3 is a common VIP in DE networks). The remaining hubs and VIPs with known biological function in DE networks (Table 1) are related to: neuronal differentiation (two genes), neuronal motility (two genes), reactive astrogliosis (one gene), neuronal cholesterol balance (one) and cell adhesion (one). All these genes play relevant roles in regulating neuronal functions. Alterations in most of these genes are associated with epilepsy, what makes them potential therapeutic targets. The following discussion is centered in this later issue.

FS-DE networks. The first FS-DE hub to considered here, $B S \mathcal{N}$, codes for Bassoon, a cytomatrix protein that speeds vesicle reloading at excitatory synapses [44,43]. BSN and the gene PCLO (Piccolo), which is a hub in the CO-NFS network, exert a redundant role in maintaining synaptic vesicle clustering [45]. Bassoon interacts with the TrkB/BDNF system in determining cell-type-specific plasticity changes, as seen in mutant epileptic mice lacking Bassoon [112,113], indicating an interaction between $B S \mathcal{N}$ and NTKR2, a gene that codes for TrkB, the BDNF receptor, and that is also involved in mesial temporal lobe epileptogenesis $[82,84]$. NTKR2 is a high-hub in the CO-FS network, what points out for its relevance in hippocampal CA3 molecular pathways. On the other hand, valproic acid, a commonly used antiepileptic drug, rebalances TrkB and BDNF brain levels in Bassoon mutant mice and reduces epileptic seizures [113]. This underscore $B S \mathcal{N}, B D N F$ and NTRK2 interconnection in epilepsy, corroborated in this study.

Two other hubs, ADAM23 and BRUNOL4, act on neuronal excitability. ADAM23 controls dendritic arborization in CA1 pyramidal neurons and is a LG1L receptor [50]. BRUNOL4 (aliase CELF4) codes for a RNA-binding protein and is primarily expressed in excitatory neurons - including large pyramidal cells in the cerebral cortex and hippocampus - and regulates excitatory but not inhibitory neurotransmission. This gene regulates translation and local abundance of several synaptic function-associated genes. BRUNOL4 deficiency causes complex seizure disorders in mutant mice and humans $[46,47]$. Both genes play important roles in controlling neuronal excitability. ADAM23 is an interactor of LGI1, an important antiepileptogenic protein [49,50] and BRUNOL4 codes for a RNA-binding protein highly expressed in the hippocampus that regulates several genes related to synaptic functions [47]. The LGI1/ADAM23 (ligand-receptor) complex is considered "an exciting therapeutic target for human epilepsy" [50] and the same can be stated about BRUNOL4, since alterations in this gene are involved not only in epilepsy but also in other neurological conditions, such as autism [47].

There are also two relevant nodes common to FS-DE and NFSDE networks: $A B C G 4$, a hub, and $M E G-3$, a VIP, both associated to brain homeostasis and stress responses. ABCG4 controls neuronal but not astrocytic cholesterol efflux [51]. Changes in brain cholesterol levels during status epilepticus occurs in temporal lobe epilepsy [52]. Disruption of brain cholesterol homeostasis occurs in other neurological, neurodegenerative and neurodevelopmental disorders and suggests a potential role of $A B C G 4$ in brain disorders [51]. MEG3 (aliase GTL2), is a maternally imprinted long noncoding RNA gene [60]. Long noncoding RNAs seem to play relevant functions central nervous system development, homeostasis, stress responses, and plasticity [61,62]. MEG3 orthologous gene in mice, $G t l 2$, is strongly expressed in the pyramidal cell layer of the hippocampus and this expression is consistent with a role in neuronal development and differentiation [114].

The remaining FS-DE main hubs are BAIAP2 and ASPHD2. The first is involved in excitatory synaptic transmission and in neurite growth and spine morphogenesis [48] whereas the second 
codes for an oxidoreductase that regulates neuronal motility driven by transient (mild) oxidative stress [53].

The FS-DE network has three distinctive VIPs, CACNG2, $K C N H 3$ and GNG3, with relevant roles in epilepsy. CACNG2, which codes for the protein stargazin, is essential for stabilizing diffuse AMPA receptors in the post synaptic density, an important feature of glutamatergic synaptic transmission [54,115] and genetic absence/alteration enhances thalamic excitability and contributes to epilepsy phenotype [55]. This gene was previously found to be up-regulated in febrile RMTLE [16] and stargazin overexpression in FS patients was confirmed by immunohistochemistry in the present work. Stargazin and AMPA receptor membrane targeting contribute to neuronal hyperexcitability, with a pathophysiological role in the epilepsy phenotype [116]. Stargazin is considered a novel potential target for antiepileptic drugs [117]. $K C N H 3$, which codes for a potassium channel $\mathrm{Kv} 7$, is a potent regulator of hippocampal and cortical excitability $[58,59]$ and is also a target of the endogenous antiepileptic neuropeptide somatostatin in hippocampal pyramidal neurons $[58,16]$. GNG3 is widely expressed in the brain and required for $\mathrm{GABA}_{\mathrm{B}} \mathrm{R}$ neuronal excitability regulation. The role of GNG3 protein, and of other Gprotein subtypes, in neuronal excitability regulation is currently being investigated in animal models: GNG3 genetic deficiency causes increased susceptibility to seizures in mice [56,57].

NFS-DE network. This network harbors hubs and VIPs with prominent roles in neuronal excitation, synaptic transmission and neuronal differentiation. Two of these hubs, ADAM23 and ABCG4, are also present in the FS-DE network and were commented above. Three out the other four hubs are directly involved in neuronal excitability (the exception is ACTA1, involved in hippocampal neuronal motility regulation [118]). Accordingly, A2BP1 codes for a RNA-binding protein, Rbfoxl, that regulates the alternative splicing of neuronal transcripts involved in synaptic transmission and membrane excitation, some of which involved in epilepsy [64]. The study of post-transcriptional regulation by $\mathrm{Rbfox} 1$ is an area of interest for understanding the control of cell homeostasis and misregulation in neurological diseases [64]. This gene probably exerts a role similar to BRUNOL4 in the FS-DE network, its mutation causing epilepsy [64]. AMPH1 codes for amphiphysin I, which is an important regulator of synaptic vesicle endocytosis [119] when massive amounts of $\mathrm{Ca}^{+}$flow into presynaptic terminals, a phenomenon observed in epilepsy [120]. AADACL1 regulates de novo formation of platelet-activation factor (PAF), an inflammation mediator. PAF accumulates in the brain after seizures and causes hippocampal hyperexcitability [121]. AADACL1 attenuates hippocampal excitability by reducing de novo PAF formation [122].

Three of the six NFS-DE VIPs are linked to neural excitability and circuitry control. One of them, $\mathcal{F} P H 3$, codes for junctophilin 3 . Junctophilins 3 and 4 are involved in subsurface cistern formation in hippocampal pyramidal neurons [123] and exert a pivotal role in neural excitability fundamental to plasticity and integrated functions [124]. The two other VIPs are involved in hippocampal synaptic transmission and neuromodulation. CHRM3, codes for the muscarinic acetylcholine receptor that confers differential cholinergic modulation to neurochemically distinct hippocampal basket cells subtypes [74]. Early life seizures increase the efficacy of muscarinic receptors coupling to protein $G$ accounting to adult susceptibility to epilepsy, what makes this gene a potential target for novel anticonvulsant drugs [16,125]. C6orf154 codes for a leucine rich repeat containing protein (LRR). It was recently discovered that some LRR-containing proteins, as Elfn1, are involved in controlling hippocampal synaptic functions and, moreover, in similar ways as perfomed by LRR containing-Trk neurotrophin receptors and the antiepileptic protein LG1L [72,73]. Consequently, C6orf154 is an interesting candidate for further investigations on target-specific synaptic transmission [72].

Among the other three VIPs, two are genes acting on neuronal differentiation and one (GPR68) is associated to astroglial cell functions. $M Y T 1 L$, it is an important gene for neurogenesis and neural cell maturation [75], being involved in the maturation of dopaminergic neurons [76] and NEUROD6 is a gene involved in neuronal stress tolerance in CA1-CA3 pyramidal neurons [78,79]. NEUROD6, a gene responsible for granule cell differentiation in the hippocampus [126], was described as not expressed in heterotopic neurons in epilepsy-induced hippocampal heterotopia [78]. Our patients, in FS and NFS groups, presented heterotopic neurons in the granule cell layer and CA3 expression of NEUROD 6 was found in both groups, being significantly higher in FS cases, as determined by quantitative real-time polymerase chain reaction [16].

\section{CO networks}

There are 19 genes with known biological functions in $\mathrm{CO}$ networks (Table 2) and 12 of these genes are involved with hippocampal cell differentiation or neuroprotection. The other seven genes are mostly involved with hippocampal excitability and epileptogenesis. We shall focus here mainly on genes with relevant roles in epilepsy- associated mechanisms.

FS-CO network. The selected nodes in this network include just high-hubs and VIPs. High-hubs may play more important roles than hubs and VIPs in transcriptional interaction networks [30]. A very relevant high-hub in FS-CO network is NTRK2, which codes for the BDNF receptor TrkB, a therapeutic target candidate. In several MTLE animal models seizures induce a pronounced increase of BDNF expression and enhance the activation of TrkB in the mossy fiber pathway of hippocampus. Transgenic overexpression of BDNF or Trkb increased seizure susceptibility and severity, whereas diminished TrkB signaling reduced epileptogenesis, thus indicating a causal role for BDNF and TrkB in limbic epileptogenesis $[82,87,127,128]$. BDNF and TrkB are therefore potential targets for antiepileptic and antiepileptogenic therapies [82].

Two among the other five high-hubs, SDADI and $\mathcal{N}-P A C$ are related to BDNF-driven processes whereas the other three CIAPIM1, $\mathcal{F} A K 3$ and DST - are associated to different compensatory mechanisms. Actually, SDAD1 is involved in ribosomal biogenesis [80], a biological process that has been associated to brain-derived neurotrophic factor (BDNF)-induced hippocampal neurite outgrowth [60]. $\mathcal{N}-P A C$ (aliase GLYR1), regulates histone demethylation [129], a catalytic-activity-based epigenetic drift process that occurs in febrile seizure-induced epileptogenesis [84]. Interestingly, this epigenetic mechanism also regulates the elevation of BDNF gene expression after seizures [85]. CIAPIM1, codes for anamorsin, a cytokine-induced apoptosis inhibitor [86]. The nuclear translocation of anamorsin is a reactive oxygen species-dependent event and regulates the transcription of several genes involved in the protection of hippocampal dopaminergic neurons [87]. $\mathcal{F} A K 3$ codes for a non-receptor tyrosin kinase and is involved in proliferation and differentiation of neural precursor cells [88] as well as in survival of CA3 pyramidal neurons [89]. DST, codes for dystonin, a cytoskeletal linker protein [130], and it is essential for maintaining neuronal cytoskeleton organization.

Four out of the six FS-CO VIPs (Table 2) have known biological functions. Three are involved with hippocampal neuronal patterning and/or differentiation (LIMD2, PHF20L) and protection of hippocampal neurons against oxidative stress (ALDH2), what may be related to compensatory mechanisms, as discussed 
above. The other VIP, OR4C46, codes for an olfactory receptor $(\mathrm{OR})$ and is ectopically expressed in CA3. Although functional interpretation for ectopic OR expression based only on transcription information must be taken with precaution [134], it is relevant that some ORs have been implied in the regulation of synaptic efficiency by modulating $\mathrm{Ca}^{2+}$ levels $[97,98]$. Moreover, it is worth to consider that: i) several OR genes are expressed in the hippocampus of MTLE patients [132]; ii) genes controlling selective connectivity at dentate gyrus-CA3 and CA3-CA1 synapses map near OR clusters [133], and iii) olfactory sensory neurons are involved with seizure causation in mice [134].

NFS-CO network. Some hubs of this network present rather high betweenness centrality values (Table 2), what can be considered a measure of their network essentiality and an indicative of relevant biological roles for these hubs [20,21]. Three of these hubs probably participate in compensatory mechanisms: $\mathcal{N} A V 2$ is a key player in the processes of neurite outgrowth and axonal elongation [99]; $O D Z 3$ codes for a teneurin, which is a neuronal connectivity regulator [102]; and TREML2 acts on the phagocytosis of apoptotic neuronal cells by microglia [103]. The other three hubs are linked to synaptic function and neuronal excitability. RGS14 acts at the interface of hippocampal signaling and synaptic plasticity [100]. SLAE codes for a sialic acid acetyl estearase. Sialic acid modifications are involved in hippocampal CA3 neural regulation and network excitability [101]. PCLO (Piccolo) acts on the maintenance of synaptic vesicle clustering [45]. $P C L O$ acts redundantly with $B S \mathcal{N}$, which is a hub in FS-DE network, on synaptic vesicle clustering and integrity maintenance $[45,135]$.

Finally, the three NFS-CO VIPs may be also involved in compensatory mechanisms: MUS81 codes for a DNA recombination repair endonuclease highly accumulated in nucleoli [104] and is involved in the Alternative Lengthening of Telomeres (ALT)-cell survival process [105], FARSA codes for an aminoacyl-tRNA synthetase related to axonal development and $S A M C 1 L$ is highly expressed in hippocampus. This gene regulates Golgi membrane morphology $[108,109]$, shares sequence homology with synaptojanins [108] and it is involved in astrogliogenesis [110].

Taken together, the results for DE networks reflect a majority of processes linked to synaptic transmission and neuronal excitability, whereas the profile of $\mathrm{CO}$ networks show predominance of compensatory mechanisms for the neuronal cell loss/damage associated with epilepsy-induced hippocampal sclerosis [136]. Compensatory mechanisms encompass dentate gyrus neurogenesis [137], synaptic reorganization, axonal sprouting, reactive astrogliosis, and the generation of new excitatory synaptic connections, that can alleviate or aggravate epilepsy $[138,139]$.

\section{Interactome validation and histopathology}

Interactome analyses (Figs. 8 A-D) validated most of the selected high-hubs, VIPs and hubs obtained through DE and CO transcriptional interaction network analyses: many high-hubs and hubs of transcriptional networks are also hubs in the interactome networks. The DE-FS interactome showed that the majority of the proteins are involved in synaptic transmission and neuronal excitability, whereas the DE-NFS interactome network is more related to neuronal differentiation processes. Both FS-CO and NFS-CO interactome networks showed predominance of pathways linked to neuronal differentiation, synaptic transmission and cell processes associated to compensatory mechanisms, although different subsets of proteins were involved in FS or NFS pathways. Histopathological findings confirmed that stargazin (CACNG2) is significantly more expressed in CA1, CA3 and granule cell layer of FS cases, what is in accordance with our genomic, transcriptional and interactome network data and with our previous work [16]. Finally, it is worth to note that the FS patient's group shows significantly increased granule cell loss (Fig. 9A), probably reflecting enhanced CA3 neuronal excitability and diminished compensatory mechanism activity, as indicated by genomic and interactome data.

\section{Complex network driven-view of RMTLE}

In conclusion, complex network analysis conducted in this study yielded a broad and more detailed view of genomic and molecular mechanisms involved in RMTLE in comparison to analyses centered on differentially expressed genes. Specifically, hubs and VIPs in DE networks are mostly related to neuronal excitability and, in a broad sense, play pro-epileptic roles. Conversely, hubs, VIPs and high-hubs in CO networks are more frequently related to neuronal differentiation, neuroprotection and synaptic function, in a scenario compatible with compensatory mechanisms that may play a reparatory role, but may also be linked to epilepsy pathogenesis $[138,139]$. The DE genes with higher connectivity occupy a central position in both DE and CO networks, reflecting their biological essentiality and role in disease [125]. The same network centrality is observed for the hubs, VIPs and high-hubs of $\mathrm{CO}$ networks, being consistent with the network disease model [21], where a group of nodes whose perturbation leads to a disease phenotype forms a disease module occupying a central network position $[21,140]$. This finding indicates that the probability of exerting therapeutic effects through the modulation of particular genes will be higher if these genes are highly interconnected in transcriptional networks [15].

\section{Supporting Information}

Video S1 Complete transcriptional interaction network for FS based on Pearson's correlation of 15,585 GO annotated genes. High-hubs and VIPs are identified by their gene symbols. FS-DE network hubs and VIPs are also shown.

(DOG)

Video S2 Complete transcriptional interaction network for NFS based on Pearson's correlation of 11,233 GO annotated genes. Hubs and VIPs are identified by their gene symbols. NFS-DE network hubs and VIPs are also shown.

(DOG)

Table S1 Functional description of interactome nodes corresponding to hubs and VIPs in FS transcriptional interaction network for differentially expressed genes (DE).

(DOG)

Table S2 Functional description of interactome nodes corresponding to hubs and VIPs in NFS transcriptional interaction network for differentially expressed genes (DE).

(DOC)

Table S3 Functional description of interactome nodes corresponding to high-hubs and VIPs in FS complete transcriptional interaction network $(\mathrm{CO})$.

(DOC)

Table S4 Functional description of interactome nodes corresponding to hubs and VIPs in NFS complete transcriptional interaction network $(\mathrm{CO})$.

(DOC) 


\section{Acknowledgments}

We are indebted to Fernanda Bernardi Bertonha, Leandro R. Ferreira, and Priscila Iamashita, from the Laboratory of Pediatric Genomics, Department of Pediatrics, FMUSP, for valuable technical help.

\section{References}

1. Carpio A, Hauser WA (2009) Epilepsy in the developing world. Curr Neurol Neurosci Rep 9: 319-326.

2. Téllez-Zenteno JF, Hernández-Ronquillo L (2012) A review of the epidemiology of temporal lobe epilepsy. Epilepsy Res Treat 2012: 630853.

3. Hemming K, Maguire MJ, Hutton JL, Marson AG (2013) Vigabatrin for refractory partial epilepsy. Cochrane Database Syst Rev 1: CD007302.

4. Engel JJr, McDermott MP, Wiebe S, Langfitt JT, Stern JM, et al. (2012) Early Randomized Surgical Epilepsy Trial (ERSET) Study Group. Early surgical therapy for drug-resistant temporal lobe epilepsy: a randomized trial. JAMA 307: 922-930.

5. Engel J (2001) Mesial temporal lobe epilepsy: what have we learned? The Neuroscientist 7: 340-352.

6. Cendes F (2004) Febrile seizures and mesial temporal sclerosis. Curr Opin Neurol 17: 161-164.

7. Baulac S, Gourfinkel-An I, Nabbout R, Huberfeld G, Serratosa J, et al. (2004) Fever, genes and epilepsy. Lancet Neurol 3: 421-430.

8. Dubé CM, Ravizza T, Hamamura M, Zha Q Keebaugh A, et al. (2010) Epileptogenesis provoked by prolonged experimental febrile seizures: mechanisms and biomarkers. J Neurosci 30: 7484-7494.

9. McClelland S, Dubé CM, Yang J, Baram TZ (2011) Epileptogenesis after prolonged febrile seizures: mechanisms, biomarkers and therapeutic opportunities. Neurosci Lett 497: 155-162.

10. Chungath M, Shorvon S (2008) The mortality and morbidity of febrile seizures. Nat Clin Pract Neurol 4: 610-621.

11. Engel J Jr (2011) Another good reason to consider surgical treatment for epilepsy more often and sooner. Arch Neurol 68: 707-708.

12. Loeb JA (2011) Identifying targets for preventing epilepsy using systems biology. Neurosci Lett 497: 205-212.

13. Winden KD, Karsten SL, Bragin A, Kudo LC, Gehman L, et al. (2011) A systems level, functional genomics analysis of chronic epilepsy.PLoS One 6: e20763.

14. Ferraro TN (2012) Discovery of epilepsy susceptibility genes: implications for therapy development and pharmacogenomics. Pharmacogenomics 13: 731734 .

15. Margineanu DG (2012) Systems biology impact on antiepileptic drug discovery. Epilepsy Res 98: 104-115.

16. Bando SY, Alegro MC, Amaro E Jr, Silva AV, Castro LH, et al. (2011) Hippocampal CA3 transcriptome signature correlates with initial precipitating injury in refractory mesial temporal lobe epilepsy. PLoS One 6: e26268.

17. Alegro MC, Silva AV, Bando SY, Lopes RD, Castro LH, et al. (2012) Texture analysis of high resolution MRI allows discrimination between febrile and afebrile initial precipitating injury in mesial temporal sclerosis. Magn Reson Med 68: 1647-1653.

18. Albert R, Jeong H, Barabási AL (2000) Error and attack tolerance of complex networks. Nature 406: 378-382.

19. Barabási AL, Oltvai ZN (2004) Network biology: understanding the cell's functional organization. Nat Rev Genet 5: 101-113.

20. Yu H, Kim PM, Sprecher E, Trifonov V, Gerstein M (2007) The importance of bottlenecks in protein networks: correlation with gene essentiality and expression dynamics. PLoS Comput Biol 3: e59

21. Barabási AL, Gulbahce N, Loscalzo J (2011) Network Medicine: a network based approach to human disease. Nat Rev Genet 13: 56-68.

22. Cai JJ, Borenstein E, Petrov DA (2010) Broker genes in human disease. Genome Biol Evol 2: 815-825.

23. Costa L da F, Oliveira Jr ON, Travieso G, Rodrigues FA, Villas Boas PR, et al. (2011) Analyzing and modeling real-world phenomena with complex networks: a survey of applications. Advances in Physics 60: 329-412.

24. Saeed Al, Sharov V, White J, Li J, Liang W, et al. (2003) TM4: a free, opensource system for microarray data management and analysis. Biotechniques 34 : 374-378.

25. Prifti E, Zucker JD, Clement K, Henegar C (2008) FunNet: an integrative tool for exploring transcriptional interactions. Bioinformatics 24: 2636-2638.

26. Costa L da F, Tognetti MAR, Silva FN (2008) Concentric characterization and classification of complex network nodes: Application to an institutional collaboration network. Physica A 387: 6201-6214.

27. Costa, L da F (2004) The hierarchical backbone of complex networks. Phys Rev Lett 93: 098702.

28. Costa L da F, Silva FN (2006) Hierarchical characterization of complex networks. J Stat Phys 125: 845-876.

29. Liu YY, Slotine JJ, Barabási AL (2011) Controllability of complex networks. Nature 473: 167-173.

30. Mcauley JJ, Costa L da F, Caetano TS (2007) Rich-club phenomenon across complex network hierarchies. Appl Phy Lett 91: 084103.

\section{Author Contributions}

Conceived and designed the experiments: SYB CAM-F AVS. Performed the experiments: SYB LRP-S. Analyzed the data: SYB FNS LdaFC CAMF. Contributed reagents/materials/analysis tools: FNS LdaFC LHMC HTW EA. Wrote the paper: CAM-F SYB.

31. Masuda N, Konno N (2006) VIP-club phenomenon: Emergence of elites and masterminds in social networks. Social Networks 28: 297-309.

32. Freeman LC (1978) Centrality in social networks: conceptual clarification. Social Networks 1: 215-239.

33. Brandes U (2001) A Faster Algorithm for Betweenness Centrality. J Math Sociol 25: 163-177.

34. Kamada T, Kawai S (1989) An algorithm for drawing general undirected graphs. Inform Process Lett 31: 7-15.

35. Fruchterman TMJ, Reingold EM (1991) Graph Drawing by Force-Directed Placement Software. Practice \& Experience 21: 1129-1164.

36. Silva FN, Rodrigues FA, Oliveira Junior ON, Costa L da F (2013) Quantifying the interdisciplinarity of scientific journals and fields. J Informetr 7: 469-477.

37. Griebel M, Knapek S, Zumbusch G (2007) Numerical Simulation in Molecular Dynamics. Berlin, Heidelberg: Springer, 476

38. Lambert JD (1992) Numerical Methods for Ordinary Differential Systems: The Initial Value Problem. New York: Wiley, 304

39. Greengard L, Rokhlin V (1987) A Fast Algorithm for Particle Simulations. J Comput Phys 73: 325-348.

40. Silva AV, Houzel JC, Croaro I, Yacubian EMT, Stavale JN, et al. (2007) Granular cell dispersion and bilamination: two distinct histopathological patterns in epileptic hippocampi? Epileptic Disord 9: 438-442.

41. Blümcke I, Kistner I, Clusmann H, Schramm J, Becker AJ, et al. (2009) Towards a clinico-pathological classification of granule cell dispersion in human mesial temporal lobe epilepsies. Acta Neuropathol 117: 535-544.

42. Clauset A, Shallizi CR, Newman MEJ (2009) Power-Law Distributions in Empirical Data. SIAM Review 51: 661-703.

43. Frank T, Rutherford MA, Strenzke N, Neef A, Pangršič T, et al. (2010) Bassoon and the synaptic ribbon organize $\mathrm{Ca}^{2}+$ channels and vesicles to add release sites and promote refilling. Neuron 68: 724-738.

44. Hallermann S, Fejtova A, Schmidt H, Weyhersmüller A, Silver RA, et al. (2010) Bassoon speeds vesicle reloading at a central excitatory synapse. Neuron 68: 710-723.

45. Mukherjee K, Yang X, Gerber SH, Kwon HB, Ho A, et al. (2010) Piccolo and bassoon maintain synaptic vesicle clustering without directly participating in vesicle exocytosis. Proc Natl Acad Sci USA 107: 6504-6509.

46. Yang Y, Mahaffey CL, Bérubé N, Maddatu TP, Cox GA, et al. (2007) Complex seizure disorder caused by Brunol4 deficiency in mice. PLoS Genet 3: e124.

47. Wagnon JL, Briese M, Sun W, Mahaffey CL, Curk T, et al. (2012) CELF4 Regulates Translation and Local Abundance of a Vast Set of mRNAs, Including Genes Associated with Regulation of Synaptic Function. PLoS Genet 8: e1003067.

48. Kim MH, Choi J, Yang J, Chung W, Kim JH, et al. (2009) Enhanced NMDA receptor-mediated synaptic transmission, enhanced long-term potentiation, and impaired learning and memory in mice lacking IRSp53. J Neurosci 29: 1586-1595.

49. Owuor K, Harel NY, Englot DJ, Hisama F, Blumenfeld H, et al. (2009) LGI1associated epilepsy through altered ADAM23-dependent neuronal morphology. Mol Cell Neurosci 42: 448-457.

50. Fukata Y, Lovero KL, Iwanaga T, Watanabe A, Yokoi N, et al. (2010) Disruption of LGIl-linked synaptic complex causes abnormal synaptic transmission and epilepsy. Proc Natl Acad Sci USA 107: 3799-3804.

51. Chen J, Zhang X, Kusumo H, Costa LG, Guizzetti M (2013) Cholesterol efflux is differentially regulated in neurons and astrocytes: Implications for brain cholesterol homeostasis. Biochim Biophys Acta 1831: 263-275.

52. Heverin M, Engel T, Meaney S, Jimenez-Mateos EM, Al-Saudi R, et al. (2012) Bi-lateral changes to hippocampal cholesterol levels during epileptogenesis and in chronic epilepsy following focal-onset status epilepticus in mice. Brain Res 1480: 81-90.

53. Lawton M, Tong M, Gundogan F, Wands JR, de la Monte SM (2010) Aspartyl-(asparaginyl) beta-hydroxylase, hypoxia-inducible factor-alpha and Notch cross-talk in regulating neuronal motility. Oxid Med Cell Longev 3: 347-356.

54. Stein EL, Chetkovich DM (2010) Regulation of stargazin synaptic trafficking by C-terminal PDZ ligand phosphorylation in bidirectional synaptic plasticity. J Neurochem 113: 42-53.

55. Lacey CJ, Bryant A, Brill J, Huguenard JR (2012) Enhanced NMDA receptordependent thalamic excitation and network oscillations in stargazer mice. J Neurosci 32: 11067-11081.

56. Schwindinger WF, Giger KE, Betz KS, Stauffer AM, Sunderlin EM, et al. (2004) Mice with deficiency of $\mathrm{G}$ protein gamma3 are lean and have seizures. Mol Cell Biol 24: 7758-7768.

57. Schwindinger WF, Mirshahi UL, Baylor KA, Sheridan KM, Stauffer AM, et al. (2012) Synergistic roles for G-protein $\gamma 3$ and $\gamma 7$ subtypes in seizure 
susceptibility as revealed in double knock-out mice. J Biol Chem 287: 71217133.

58. Qiu C, Zeyda T, Johnson B, Hochgeschwender U, de Lecea L, et al. (2008) Somatostatin receptor subtype 4 couples to the M-current to regulate seizures. J Neurosci 28:3567-3576.

59. Zhang X, Bertaso F, Yoo JW, Baumgärtel K, Clancy SM, et al. (2010) Deletion of the potassium channel Kv12.2 causes hippocampal hyperexcitability and epilepsy. Nat Neurosci 13: 1056-1058.

60. Zhou Y, Zhang X, Klibanski A (2012) MEG3 noncoding RNA: a tumor suppressor. J Mol Endocrinol 48: R45-53.

61. Qureshi IA, Mattick JS, Mehler MF (2010) Long non-coding RNAs in nervous system function and disease. Brain Res 1338: 20-35.

62. Lipovich L, Dachet F, Cai J, Bagla S, Balan K, et al. (2012) Activity-dependent human brain coding/noncoding gene regulatory networks. Genetics 192: $1133-1148$

63. Pavlakis E, Chiotaki R, Chalepakis G (2011) The role of Fras1/Frem proteins in the structure and function of basement membrane. Int J Biochem Cell Biol 43: 487-495.

64. Gehman LT, Stoilov P, Maguire J, Damianov A, Lin CH, et al. (2011) The splicing regulator Rbfoxl (A2BP1) controls neuronal excitation in the mammalian brain. Nat Genet 43: 706-711.

65. Pant S, Sharma M, Patel K, Caplan S, Carr CM, et al. (2009) AMPH-1/ Amphiphysin/Binl functions with RME-1/Ehd1 in endocytic recycling. Nat Cell Biol 11: 1399-1410.

66. Wu Y, Matsui H, Tomizawa K (2009) Amphiphysin I and regulation of synaptic vesicle endocytosis. Acta Med Okayama 63: 305-323.

67. Nomura DK, Fujioka K, Issa RS, Ward AM, Cravatt BF, et al. (2008) Dual roles of brain serine hydrolase KIAA1363 in ether lipid metabolism and organophosphate detoxification. Toxicol Appl Pharmacol 228: 42-48.

68. Musto AE, Samii M (2011) Platelet-activating factor receptor antagonism targets neuroinflammation in experimental epilepsy. Epilepsia 52: 551-561.

69. Stern S, Debre E, Stritt C, Berger J, Posern G, et al. (2009) A nuclear actin function regulates neuronal motility by serum response factor-dependent gene transcription. J Neurosci 29: 4512-4518.

70. Moriguchi S, Nishi M, Komazaki S, Sakagami H, Miyazaki T, et al. (2006) Functional uncoupling between $\mathrm{Ca} 2+$ release and afterhyperpolarization in mutant hippocampal neurons lacking junctophilins. Proc Natl Acad Sci USA 103: 10811-10816.

71. Nishi M, Hashimoto K, Kuriyama K, Komazaki S, Kano M, et al. (2002) Motor discoordination in mutant mice lacking junctophilin type 3. Biochem Biophys Res Commun 292: 318-324.

72. McBain CJ (2012) Neuroscience. Decoding the neuronal Tower of Babel. Science 338: 482-483.

73. Sylwestrak EL, Ghosh A (2012) Elfnl regulates target-specific release probability at CA1-interneuron synapses. Science 338: 536-540.

74. Cea-del Rio CA, Lawrence JJ, Tricoire L, Erdelyi F, Szabo G, et al. (2010) M3 muscarinic acetylcholine receptor expression confers differential cholinergic modulation to neurochemically distinct hippocampal basket cell subtypes. J Neurosci 30: 6011-6024.

75. Romm E, Nielsen JA, Kim JG, Hudson LD (2005) Mytl family recruits histone deacetylase to regulate neural transcription. J Neurochem 93: 1444-1453.

76. Pfisterer U, Kirkeby A, Torper O, Wood J, Nelander J, et al. (2011) Direct conversion of human fibroblasts to dopaminergic neurons. Proc Natl Acad Sci U S A 108: 10343-10348.

77. Schneider JW, Goetsch SC, Leng X, Ludwig SM, Russell JL, et al. (2012) Coupling Hippocampal Neurogenesis to Brain $\mathrm{pH}$ through Proneurogenic Small Molecules That Regulate Proton Sensing G Protein-Coupled Receptors. ACS Chem Neurosci 3: 557-568.

78. Castro PA, Pleasure SJ, Baraban SC (2002) Hippocampal heterotopia with molecular and electrophysiological properties of neocortical neurons. Neuroscience 114: 961-972.

79. Uittenbogaard M, Baxter KK, Chiaramello A. (2010) NeuroD6 genomic signature bridging Neuronal differentiation to survival via the molecular chaperone network. J Neurosci Res 88: 33-54.

80. Babbio F, Farinacci M, Saracino F, Carbone ML, Privitera E (2004) Expression and localization studies of hSDA, the human ortholog of the yeast SDA1 gene. Cell Cycle 3: 486-490.

81. Gomes C, Smith SC, Youssef MN, Zheng JJ, Hagg T, et al. (2011) RNA polymerase 1-driven transcription as a mediator of BDNF-induced neurite outgrowth. J Biol Chem 286: 4357-4363.

82. McNamara JO, Scharfman HE. (2012) Temporal Lobe Epilepsy and the BDNF Receptor, TrkB. In: Noebels JL, Avoli M, Rogawski MA, Olsen RW, Delgado-Escueta AV, editors. Jasper's Basic Mechanisms of the Epilepsies [Internet]. 4th edition. Bethesda (MD): National Center for Biotechnology Information (US). Available: http://www.ncbi.nlm.nih.gov/books/ NBK98186/PubMed PMID: 22787630. Accessed 10 May 2013.

83. Helgager J, Liu G, McNamara JO (2013) The cellular and synaptic location of activated TrkB in mouse hippocampus during limbic epileptogenesis. J Comp Neurol 521: Spc1.

84. Kobow K, Blümcke I (2012) The emerging role of DNA methylation in epileptogenesis. Epilepsia 53: 11-20.

85. Walczak A, Szczepankiewicz AA, Ruszczycki B, Magalska A, Zamlynska K, et al. (2013) Novel higher-order epigenetic regulation of the Bdnf gene upon seizures. J Neurosci 33: 2507-2511.
86. Shibayama H, Takai E, Matsumura I, Kouno M, Morii E, et al. (2004) Identification of a cytokine-induced antiapoptotic molecule anamorsin essential for definitive hematopoiesis. J Exp Med 199: 581-592.

87. Park KA, Yun N, Shin DI, Choi SY, Kim H, et al. (2011) Nuclear translocation of anamorsin during drug-induced dopaminergic neurodegeneration in culture and in rat brain. J Neural Transm 118: 433-444.

88. Kim YH, Chung JI, Woo HG, Jung YS, Lee SH, et al. (2010) Differential regulation of proliferation and differentiation in neural precursor cells by the Jak pathway. Stem Cells 28: 1816-1828.

89. Yamada M, Takeshita T, Miura S, Murata K, Kimura Y, et al. (2001) Loss of hippocampal CA3 pyramidal neurons in mice lacking STAM1. Mol Cell Biol 21: 3807-3819.

90. Dalpé G, Leclerc N, Vallée A, Messer A, Mathieu M, et al. (1998) Dystonin Is Essential for Maintaining Neuronal Cytoskeleton Organization. Mol Cell Neurosci 10: 243-257.

91. Tursun B, Schlüter A, Peters MA, Viehweger B, Ostendorff HP, et al. (2005) The ubiquitin ligase Rnf6 regulates local LIM kinase 1 levels in axonal growth cones. Genes Dev 19: 2307-2319. Erratum in: Genes Dev 19: 2643.

92. Tastet J, Vourc'h P, Laumonnier F, Vallée B, Michelle G, et al. (2012) LIMK2d, a truncated isoform of Lim kinase 2 regulates neurite growth in absence of the LIM kinase domain. Biochem Biophys Res Commun 420: 247252.

93. Bai J, Mei Y (2011) Overexpression of aldehyde dehydrogenase-2 attenuates neurotoxicity induced by 4-hydroxynonenal in cultured primary hippocampal neurons. Neurotox Res 19: 412-422.

94. Sanchez R, Zhou MM (2011) The PHD finger: a versatile epigenome reader. Trends Biochem Sci 36: 364-372.

95. Hakimi MA, Bochar DA, Chenoweth J, Lane WS, Mandel G, et al. (2002) A core-BRAF35 complex containing histone deacetylase mediates repression of neuronal-specific genes. Proc Natl Acad Sci U S A 99: 7420-7425.

96. Qiu J, Shi G, Jia Y, Li J, Wu M, et al. (2010) The X-linked mental retardation gene PHF8 is a histone demethylase involved in neuronal differentiation. Cell Res 20: 908-918.

97. Bradley J, Zhang Y, Bakin R, Lester HA, Ronnett GV, et al. (1997) Functional expression of the heteromeric "olfactory" cyclic nucleotide-gated channel in the hippocampus: a potential effector of synaptic plasticity in brain neurons. J Neurosci 17: 1993-2005.

98. Kuzmiski JB, MacVicar BA (2001) Cyclic nucleotide-gated channels contribute to the cholinergic plateau potential in hippocampal CAl pyramidal neurons. J Neurosci 21: 8707-8714.

99. Muley PD, McNeill EM, Marzinke MA, Knobel KM, Barr MM, et al. (2008) The atRA-responsive gene neuron navigator 2 functions in neurite outgrowth and axonal elongation. Dev Neurobiol 68: 1441-1453.

100. Vellano CP, Lee SE, Dudek SM, Hepler JR (2011) RGS14 at the interface of hippocampal signaling and synaptic plasticity. Trends Pharmacol Sci 32: 666674 .

101. Isaev D, Isaeva E, Shatskih T, Zhao Q, Smits NC, et al. (2007) Role of extracellular sialic acid in regulation of neuronal and network excitability in the rat hippocampus. J Neurosci 27: 11587-11594.

102. Young TR, Leamey CA (2009) Teneurins: important regulators of neural circuitry. Int J Biochem Cell Biol 41: 990-993.

103. Hsieh CL, Koike M, Spusta SC, Niemi EC, Yenari M, et al. (2009) A role for TREM2 ligands in the phagocytosis of apoptotic neuronal cells by microglia. J Neurochem 109: 1144-1156.

104. Gao H, Ghen XB, McGowan CH (2003) Mus81 endonuclease localizes to nucleoli and to regions of DNA damage in human S-phase cells. Mol Biol Cell 14: $4826-4834$.

105. Zeng S, Xiang T, Pandita TK, Gonzalez-Suarez I, Gonzalo S, et al. (2009) Telomere recombination requires the MUS81 endonuclease. Nat Cell Biol 11: 616-623.

106. Zhu B, Yao P, Tan M, Eriani G, Wang ED (2009) tRNA-independent pretransfer editing by class I leucyl-tRNA synthetase. J Biol Chem 284: 34183424.

107. Manadas B, Santos AR, Szabadfi K, Gomes JR, Garbis SD, et al. (2009) BDNF-induced changes in the expression of the translation machinery in hippocampal neurons: protein levels and dendritic mRNA. J Proteome Res 8: 4536-4552.

108. Liu Y, Boukhelifa M, Tribble E, Morin-Kensicki E, Uetrecht A, et al. (2008) The Sacl phosphoinositide phosphatase regulates Golgi membrane morphology and mitotic spindle organization in mammals. Mol Biol Cell 19: 30803096.

109. Liu Y, Boukhelifa M, Tribble E, Bankaitis VA (2009) Functional studies of the mammalian Sacl phosphoinositide phosphatase. Adv Enzyme Regul 49: 7586.

110. Herrera F, Chen O, Fischer WH, Maher P, Schubert DR (2009) Synaptojanin1 plays a key role in astrogliogenesis: possible relevance for Down's syndrome. Cell Death Differ 16: 910-920.

111. Silva FN, Rodrigues FA, Oliveira Jr ON, Costa L da F (2013) Quantifying the interdisciplinarity of scientific journals and fields. J Informetrics 7: 469-477.

112. Ghiglieri V, Picconi B, Sgobio C, Bagetta V, Barone I, et al. (2009) Epilepsyinduced abnormal striatal plasticity in Bassoon mutant mice. Eur J Neurosci 29: 1979-1993. 
113. Ghiglieri V, Sgobio C, Patassini S, Bagetta V, Fejtova A, et al. (2010) TrkB/ BDNF-dependent striatal plasticity and behavior in a genetic model of epilepsy: modulation by valproic acid. Neuropsychopharmacology 35: 1531-1540.

114. McLaughlin D, Vidaki M, Renieri E, Karagogeos D (2006) Expression pattern of the maternally imprinted gene Gt12 in the forebrain during embryonic development and adulthood. Gene Expr Patterns 6: 394-399.

115. Bats C, Groc L, Choquet D (2007) The interaction between Stargazin and PSD-95 regulates AMPA receptor surface trafficking. Neuron 53: 719-734.

116. Kennard JT, Barmanray R, Sampurno S, Ozturk E, Reid CA, et al. (2011) Stargazin and AMPA receptor membrane expression is increased in the somatosensory cortex of Genetic Absence Epilepsy Rats from Strasbourg. Neurobiol Dis 42: 48-54.

117. Casillas-Espinosa PM, Powell KL, O'Brien TJ (2012) Regulators of synaptic transmission: roles in the pathogenesis and treatment of epilepsy. Epilepsia 53: $41-58$.

118. Stern S, Debre E, Stritt C, Berger J, Posern G, et al. (2009) A nuclear actin function regulates neuronal motility by serum response factor-dependent gene transcription. J Neurosci 29: 4512-4518.

119. Pant S, Sharma M, Patel K, Caplan S, Carr CM, et al. (2009) AMPH-1/ Amphiphysin/Binl functions with RME-1/Ehd1 in endocytic recycling. Nat Cell Biol 11: 1399-1410.

120. Wu Y, Matsui H, Tomizawa K (2009) Amphiphysin I and regulation of synaptic vesicle endocytosis. Acta Med Okayama 63: 305-323.

121. Musto AE, Samii M (2011) Platelet-activating factor receptor antagonism targets neuroinflammation in experimental epilepsy. Epilepsia 52: 551-561.

122. Nomura DK, Fujioka K, Issa RS, Ward AM, Cravatt BF, et al. (2008) Dual roles of brain serine hydrolase KIAA1363 in ether lipid metabolism and organophosphate detoxification. Toxicol Appl Pharmacol 228: 42-48.

123. Nishi M, Hashimoto K, Kuriyama K, Komazaki S, Kano M, et al. (2002) Motor discoordination in mutant mice lacking junctophilin type 3. Biochem Biophys Res Commun 292: 318-324

124. Moriguchi S, Nishi M, Komazaki S, Sakagami H, Miyazaki T, et al. (2006) Functional uncoupling between $\mathrm{Ca} 2+$ release and afterhyperpolarization in mutant hippocampal neurons lacking junctophilins. Proc Natl Acad Sci U S A 103: 10811-10816.

125. Potier S, Sénécal J, Chabot JG, Psarropoulou G, Descarries L (2005) A pentylenetetrazole-induced generalized seizure in early life enhances the efficacy of muscarinic receptor coupling to G-protein in hippocampus and neocortex of adult rat. Eur J Neurosci 21: 1828-1836.

126. Schwab MH, Bartholomae A, Heimrich B, Feldmeyer D, Druffel-Augustin S, et al. (2000) Neuronal basic helix-loop-helix proteins (NEX and BETA2/Neuro D) regulate terminal granule cell differentiation in the hippocampus. J Neurosci 20: $3714-3724$.
127. Heinrich C, Lähteinen S, Suzuki F, Anne-Marie L, Huber S, et al. (2011) Increase in BDNF-mediated TrkB signaling promotes epileptogenesis in a mouse model of mesial temporal lobe epilepsy. Neurobiol Dis 42: 35-47.

128. Brooks-Kayal AR, Russek SJ (2012) Regulation of GABA(A) Receptor Gene Expression and Epilepsy. In: Noebels JL, Avoli M, Rogawski MA, Olsen RW, Delgado-Escueta AV, editors. Jasper's Basic Mechanisms of the Epilepsies [Internet]. 4th edition. Bethesda (MD): National Center for Biotechnology Information (US). Available: http://www.ncbi.nlm.nih.gov/books/ NBK98201/PubMed PMID: 22787609. Accessed 12 May 2013.

129. Fang R, Chen F, Dong Z, Hu D, Barbera AJ, et al, (2013) LSD2/KDM1B and its cofactor NPAC/GLYR1 endow a structural and molecular model for regulation of H3K4 demethylation. Mol Cell 49: 558-570.

130. Ryan SD, Ferrier A, Sato T, O'Meara RW, De Repentigny Y, et al. (2012) Neuronal dystonin isoform 2 is a mediator of endoplasmic reticulum structure and function. Mol Biol Cell 23: 553-566.

131. Feldmesser E, Olender T, Khen M, Yanai I, Ophir R, et al. (2006) Widespread ectopic expression of olfactory receptor genes. BMC Genomics 7: 121.

132. Kwon KH, Kim JY, Kim SY, Min HK, Lee HJ, et al. (2013) Chromosome 11centric human proteome analysis of human brain hippocampus tissue. J Proteome Res 12: 97-105.

133. Deguchi Y, Donato F, Galimberti I, Cabuy E, Caroni P (2011) Temporally matched subpopulations of selectively interconnected principal neurons in the hippocampus. Nat Neurosci 14: 495-504.

134. Nguyen MO, Ryba NJ (2012) A smell that causes seizure. PLoS One 7: e41899.

135. Waites CL, Leal-Ortiz SA, Okerlund N, Dalke H, Fejtova A, et al. (2013) Bassoon and Piccolo maintain synapse integrity by regulating protein ubiquitination and degradation. EMBO J 32: 954-969.

136. Bae EK, Jung KH, Chu K, Lee ST, Kim JH, et al. (2010) Neuropathologic and clinical features of human medial temporal lobe epilepsy. J Clin Neurol 6: 7380 .

137. Schneider-Mizell CM, Parent JM, Ben-Jacob E, Zochowski MR, Sander LM (2010) From network structure to network reorganization: implications for adult neurogenesis. Phys Biol 7: 046008.

138. Parent JM, Kron MM (2012) Neurogenesis and Epilepsy. In: Noebels JL, Avoli M,Rogawski MA, Olsen RW, Delgado-Escueta AV, editors. Jasper's Basic Mechanisms of the Epilepsies [nternet]. 4th edition. Bethesda (MD): National Center for Biotechnology Information (US). Available: http://www.ncbi.nlm. nih.gov/books/NBK98198/. Accessed 10 May 2013.

139. Goldberg EM, Coulter DA (2013) Mechanisms of epileptogenesis: a convergence on neural circuit dysfunction. Nat Rev Neurosci 14: 337-349.

140. Gaiteri C, Sibille E (2011) Differentially expressed genes in major depression reside on the periphery of resilient gene coexpression networks. Front Neurosci 5: 95 . 